\title{
Gamma Knife radiosurgery for vestibular schwannoma: clinical results at long-term follow-up in a series of 379 patients
}

\author{
Clinical article
}

\author{
Nicola Boari, M.D., ${ }^{1}$ Michele Bailo, M.D. ${ }^{1}$ Filippo Gagliardi, M.D., ${ }^{1}$ \\ Alberto Franzin, M.D., ${ }^{1}$ Marco Gemma, M.D., ${ }^{2}$ Antonella del Vecchio, Ph.D., ${ }^{3}$ \\ Angelo Bolognesi, M.D., ${ }^{4}$ Piero Picozzi, M.D., ${ }^{1}$ And Pietro Mortini, M.D. ${ }^{1,5}$ \\ ${ }^{1}$ Department of Neurosurgery, ${ }^{2}$ Service of Neuroanesthesia, ${ }^{3}$ Service of Medical Physics, and ${ }^{4}$ Service of \\ Radiation Oncology, I.R.C.C.S. San Raffaele Hospital; and ${ }^{5}$ Department of Neurosurgery, Vita-Salute San \\ Raffaele University, Milan, Italy
}

Object. Since the 1990s, Gamma Knife radiosurgery (GKRS) has become the first-line treatment option for small- to medium-size vestibular schwannomas (VSs), especially in patients without mass effect-related symptoms and with functional hearing. The aim of this study was to assess the safety and efficacy of GKRS, in terms of tumor control, hearing preservation, and complications, in a series of 379 consecutive patients treated for VS.

Methods. Of 523 patients treated at the authors' institution for VS between 2001 and 2010, the authors included 379 who underwent GKRS as the primary treatment. These patients were not affected by Type 2 neurofibromatosis and had clinical follow-up of at least 36 months. Clinical follow-up (mean and median 75.7 and 69.5 months, respectively) was performed for all patients, whereas audiometric and quantitative radiological follow-up examinations were obtained for only 153 and 219 patients, respectively. The patients' ages ranged from 23 to 85 years (mean 59 years). The mean tumor volume was $1.94 \pm 2.2 \mathrm{~cm}^{3}$ (median $1.2 \mathrm{~cm}^{3}$, range $0.013-14.3 \mathrm{~cm}^{3}$ ), and the median margin dose was 13 Gy (range 11-15 Gy). Parameters considered as determinants of the clinical outcome were long-term tumor control, hearing preservation, and complications. A statistical analysis was performed to correlate clinical outcomes with the radiological features of the tumor, dose-planning parameters, and patient characteristics.

Results. Control of the tumor with GKRS was achieved in $97.1 \%$ of the patients. In $82.7 \%$ of the patients, the tumor volume had decreased at the last follow-up, with a mean relative reduction of $34.1 \%$. The rate of complications was very low, with most consisting of a transient worsening of preexisting symptoms. Patients who had vertigo, balance disorders, or facial or trigeminal impairment usually experienced a complete or at least significant symptom relief after treatment. However, no significant improvement was observed in patients previously reporting tinnitus. The overall rate of preservation of functional hearing at the long-term follow-up was $49 \%$; in patients with hearing classified as Gardner-Robertson (GR) Class I, this value was $71 \%$ and reached $93 \%$ among cases of GR Class I hearing in patients younger than 55 years.

Conclusions. Gamma Knife radiosurgery is a safe and effective treatment for VS, achieving tumor control in $97.1 \%$ of cases and resulting in a very low morbidity rate. Younger GR Class I patients had a significantly higher probability of retaining functional hearing even at the 10-year follow-up; for this reason, the time between symptom onset, diagnosis, and treatment should be shortened to achieve better outcomes in functional hearing preservation. (http://thejns.org/doi/abs/10.3171/2014.8.GKS141506)

KEY WoRdS $\bullet$ Gamma Knife $\bullet$ radiosurgery $\bullet$ vestibular schwannoma $\bullet$
acoustic neuroma $\bullet \quad$ hearing preservation $\bullet$ mobile phone $\bullet$ oncology $\bullet$
stereotactic radiosurgery

$\mathrm{T}$ HE first radiosurgical treatment for vestibular schwannoma (VS) was described by Hirsch and colleagues in 1979.23 Since then, many studies have reported that radiosurgery for treating patients with VS is

\footnotetext{
Abbreviations used in this paper: $\mathrm{CN}=$ cranial nerve; GKRS = Gamma Knife radiosurgery; GR = Gardner-Robertson; HB = House-Brackmann; IAC = internal acoustic canal; IAM = internal acoustic meatus; PTA = pure tone average; NF2 = Type 2 neurofibromatosis; VS = vestibular schwannoma.
}

safe and efficacious. The available evidence indicates that Gamma Knife radiosurgery (GKRS) is the best practice for solitary VSs that are $<30 \mathrm{~mm}$ in cisternal diameter. ${ }^{64}$ In addition, many patients prefer radiosurgery to resection because of the much lower morbidity associated with radiosurgery and because rates of long-term tumor control with GKRS are similar to resection. Consequently, GKRS is currently the most common treatment for smallto medium-size VS tumors. Gamma Knife radiosurgery was established in San Raffaele Hospital in 1993 and, 
by the end of 2013, 843 patients had been treated with GKRS for VS at this institution.

In the last 15 years, reduced dose strategies have been progressively adopted, which have resulted in a significant decrease in cranial nerve $(\mathrm{CN})$ morbidity. The use of lower margin doses ( $\leq 13 \mathrm{~Gy}$ ) has led to questions of whether high rates of tumor control can be achieved with longer follow-up.,13 The present study aimed to define, in a large series, the long-term outcomes of patients with VS who underwent GKRS as a primary treatment, using relevant techniques and dosing.

\section{Methods}

\section{Patient Characteristics}

Between January 2001 and December 2010, a total of 523 consecutive patients underwent GKRS at San Raffaele Hospital. Of these patients, 102 had undergone a previous surgery, 3 had been previously treated with GKRS, and 7 were affected by Type 2 neurofibromatosis (NF2). Twentysix patients died within the follow-up period; in none of these cases was the cause of death related to the VS.

In this study, we included 379 patients meeting the following criteria: GKRS as the primary treatment and at least 36 months of clinical follow-up after GKRS. Patients affected by NF2 were excluded. The mean age of the patients was 59 years (median 61 years, range 23-85 years), and 163 were men (43\%) and 216 were women $(57 \%)$. The tumor was located on the right side in 186 patients (49.1\%) and on the left side in 193 (50.9\%).

\section{Hearing and Facial Function}

Hearing function was evaluated according to the Gardner-Robertson (GR) modification of the Silverstein and Norell classification. ${ }^{17}$ Facial nerve function was assessed according to the House-Brackmann (HB) grading system. ${ }^{24}$

\section{Radiological Measurements}

Morphological parameters and tumor volume were calculated from pre- and posttreatment MRI scans using GammaPlan software (Elekta; Fig. 1).

Tumor volume was calculated by contouring the lesion on each slice of a contrast-enhanced, T1-weighted MRI axial scan by the operating neurosurgeon with the assistance of a neuroradiologist using the "volume" function in the "measurements" window of the GammaPlan software.

\section{Tumor Classification}

Tumors were classified according to the modification by Samii and Matthies of the Koos VS grading system. ${ }^{51}$

\section{Radiosurgical Technique}

Gamma Knife radiosurgery was performed using the Leksell Gamma Knife Model C (Elekta) until September 2007 and the Gamma Knife Perfexion (Elekta) thereafter.

The GKRS procedure began with application of a local anesthetic complemented by mild intravenous se-
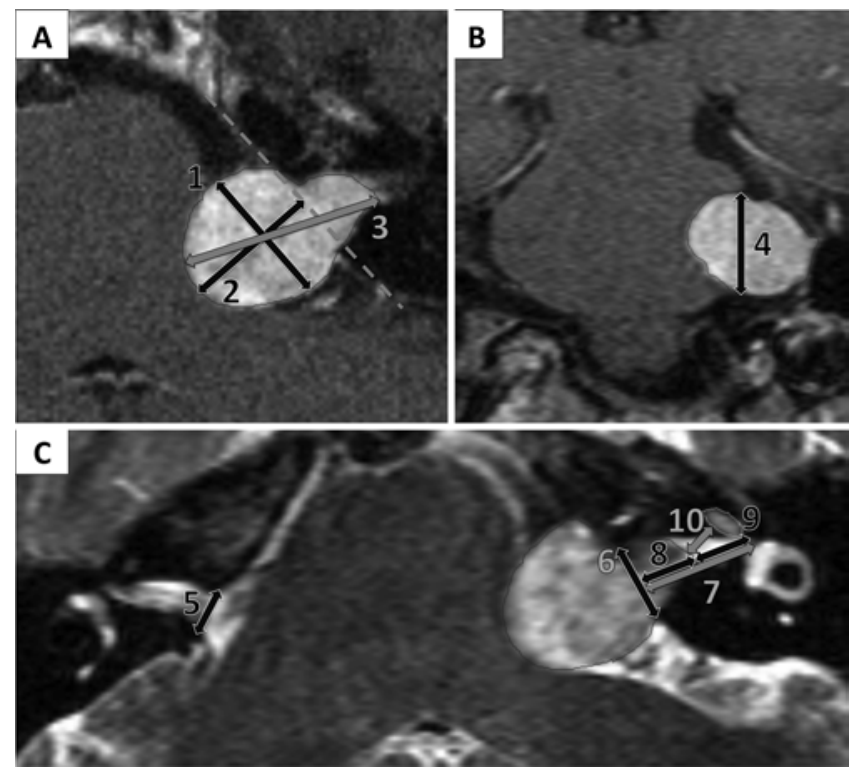

FIG. 1. Morphometric measurements calculated in the present study. A: Contrast-enhanced axial T1-weighted MRI scan showing VS maximum anteroposterior extrameatal diameter (1) (parallel to an imaginary line drawn along the posterior surface of the petrous bone), VS maximum latero-lateral extrameatal diameter (2) (perpendicular to an imaginary line drawn along the posterior surface of the petrous bone, linking the aforementioned line and the medial aspect of the VS), and VS maximum diameter (3) (including both intra- and extracanalicular portions). B: Contrast-enhanced coronal T1-weighted MRI scan showing VS maximum craniocaudal extrameatal diameter (4). C: Axial T2-weighted MRI scan showing maximum diameter of the IAM contralateral (5) and ipsilateral (6) to the VS, length of the IAC (7) (measured from the midline of the maximum diameter of the IAM to the fundus of the IAC), length of the VS intracanalicular portion (8) (from the midline of the IAM maximum diameter to the lateral end of the VS), distance between the lateral end of the VS intracanalicular portion and the fundus of the IAC (9), and minimum distance between the VS and the cochlea (10).

dation, and the patient's head was then placed in rigid fixation in an MRI-compatible Leksell stereotactic frame (Model G, Elekta). High-resolution 1.5-T MRI scans were obtained with an appropriate fiducial system (Model Magnetom Vision, Siemens). Volume-acquisition studies required a 1-mm axial slice thickness, without a gap, T1weighted with and without contrast-enhancement acquisitions that were subsequently reformatted in coronal and sagittal projections. In most cases, we also acquired constructive interference in steady-state sequences, in a coronal T1-weighted contrast-enhanced series, or both. Treatment planning was performed using Leksell GammaPlan (Elekta). Final dosimetry and all treatment-planning variables were jointly approved by the neurosurgeon, the radiation therapist, and radiation physicist. The maximum dose varied from 20 to 32.6 Gy (median 26 Gy) and the margin dose from 11 to 15 Gy (median $13 \mathrm{~Gy}$ ). The isodose line for the tumor margin varied from $40 \%$ to $63 \%$ (median 50\%). The number of isocenters varied from 1 to 41 (median 12).

\section{Follow-Up}

Patients were followed up with serial contrast-en- 
hanced MRI examinations, at 6 months, 12 months, and yearly thereafter. In cases of tumors that were stable or decreased in volume after the fourth or fifth year, MRI examinations were planned every 2 years. All patients with functional hearing were advised to obtain appropriate audiometric testing every 6 months in the first 3 years after GKRS and yearly thereafter.

The duration of clinical follow-up ranged between 36 and 157 months, with a mean of 75.7 months and a median of 69.5 months. Qualitative information about the variation in tumor volume (that is, decreased, unchanged, or increased) at MRI follow-up was obtained for all patients. Quantitative tumor volume data at followup, obtained by direct measurements on MRI scans using GammaPlan software, were collected in those patients who underwent a follow-up MRI examination at our institution (219 patients); the mean follow-up in this group was 68.3 months (median 63 and maximum 156 months). Regular audiological follow-up was achieved in 153 patients; among these, 96 patients had functional hearing at the time of GKRS (mean follow-up 59.9 months, maximum 153 months). When necessary, the patients were contacted and interviewed by telephone to update their data for the purposes of this study.

Tumor control was defined as no need for further surgical or radiosurgical intervention after primary GKRS treatment.

\section{Statistical Analysis}

We performed multivariate logistic analysis, taking each of the following as the dependent variables: occurrence of specific symptoms after GKRS, persistence of the same symptoms, treatment failure, loss of GR class, and loss of functional hearing. The symptoms studied were tinnitus, vertigo, balance disorders, lateral headache, hydrocephalus, facial nerve impairment, and trigeminal nerve impairment.

Univariate independent variable selection was performed by using a $\mathrm{p}$ value of $<0.20$ in a Pearson chisquare test or a 2-sample t-test, as appropriate, on the following variables: sex, age at GKRS, working or living in an extremely noisy environment for at least 20 years, intensive use of mobile phones $(>2$ hours daily for more than 10 years), presence of the above signs or symptoms at GKRS and time of their onset before diagnosis, time from onset of the first symptom to GKRS. The VS volume and all the radiological measures previously described were also studied. In predictive models for occurrence or persistence of tinnitus, loss of GR class, or loss of functional hearing, we also screened the mean and maximal dose to the cochlea, the mean dose to the modiolus, the pre-GKRS GR class, and the pure tone average (PTA). In predictive models for trigeminal impairment, we also screened for the maximum dose to the brainstem and the volume of the brainstem receiving 10 or $12 \mathrm{~Gy}$ (V10 and V12, respectively). In building the final model, a p value of $<0.05$ was considered statistically significant. The Kaplan-Meier product limit method was also used to calculate estimated rates of tumor control and preservation of hearing function. Univariate analysis was used to identify potential predictors of these rates by means of the log-rank test with a $\mathrm{p}$ value of $<0.20$ considered statistically significant. In this setting, continuous variables were categorized according to their interquartile ranges.

\section{Results}

\section{Presentation of Signs and Symptoms}

Table 1 reports the onset of signs and symptoms, including those prompting the patient to see a physician for the first time, those recorded at the time of diagnosis, and those present at the time when GKRS was performed. In 45 patients (11.9\%) the diagnosis of VS was incidental.

Table 2 and Fig. 2 show the length of time between the onset of each sign or symptom and the diagnosis of VS. The median time between the onset of signs or symptoms and the diagnosis was highest for hearing loss (21 months), and it was 12 months for tinnitus and balance disorders and 6 months or less for the other signs or symptoms (vertigo or facial and trigeminal nerve impairment). If hydrocephalus-associated signs or symptoms were present, the time to diagnosis was much shorter. The mean length of time from the first onset of the signs or symptoms of VS to its diagnosis was $31.6 \pm 50.9$ months (median 12 months, range $<1$ week to 30 years). The mean length of time from the onset of the symptom that eventually brought the patient to the attention of the physician to the diagnosis was $12.6 \pm 20.1$ months (median 6 months, range $<1$ week to 20 years). The mean length of time from diagnosis to the first treatment was $11.1 \pm 26$ months (median 5 months, range 4 weeks to 20 years), and that from onset of the first symptom to GKRS treatment was $41 \pm 20.1$ months (median 28 months, range 11 weeks to 37 years).

Table 3 reports the frequency of the GR classes and the patients' ages at the time of GKRS. Among the 379 patients, $187(49.3 \%)$ had serviceable hearing at the time of GKRS. Moreover, $353(93.1 \%)$ had normal facial function (HB Grade I), 23 (6.1\%) had mild facial paresis (HB Grade II), and $3(0.8 \%)$ had a moderate facial paresis (HB Grade III). Three patients had facial spasms without showing any facial paresis.

Table 4 shows the numbers and percentages of patients with VSs classified into Samii Stages T1-T4b on the basis of morphometric measures. The mean patient age at GKRS was $53.7 \pm 11.8$ years (median 52 years) in the T1 group, $58.3 \pm 12.6$ years (median 60 years) in the T2 group, $58.6 \pm 12.3$ years (median 61 years) in the T3a group, $59.9 \pm 12.4$ years (median 62 years) in the T3b group, $63.6 \pm 11.5$ years (median 65 years) in the T4a group, and $65.3 \pm 15$ years (median 64 years) in the T4b group. The age difference between the 6 groups were statistically significant (chi-square $=14.506, p=0.013$; Kruskal-Wallis H test). Dosimetric measures for each Samii stage are reported in Table 5.

\section{Tumor Characteristics}

The mean VS tumor volume was $1.94 \pm 2.2 \mathrm{~cm}^{3}$ (median $1.2 \mathrm{~cm}^{3}$, range $0.013-14.3 \mathrm{~cm}^{3}$ ). The maximum diameter ranged from 4.5 to $33.5 \mathrm{~mm}$ (mean $18.3 \pm 6.3$ $\mathrm{mm})$. In the analysis of VS, extrameatal diameter pure 
TABLE 1: Signs and symptoms in the patients in this study*

\begin{tabular}{|c|c|c|c|c|}
\hline \multirow[b]{2}{*}{ Sign/Symptom } & \multicolumn{4}{|c|}{ No. of Patients (\%) } \\
\hline & Sign/Symptom at Onset & Leading to Medical Consultation & At Diagnosis & At GKRS \\
\hline hearing loss $†$ & $250(66.0)$ & $171(45.1)$ & $278(73.4)$ & $361(95.3)$ \\
\hline tinnitus & $117(30.9)$ & $94(24.8)$ & $142(37.5)$ & $150(39.6)$ \\
\hline vertigo & $60(15.8)$ & $84(22.2)$ & $107(28.2)$ & $72(19.0)$ \\
\hline disequilibrium & $39(10.3)$ & $51(13.5)$ & $77(20.3)$ & $102(26.9)$ \\
\hline lat headache & $9(2.4)$ & $13(3.4)$ & $15(3.7)$ & $10(2.6)$ \\
\hline Adams triad $\ddagger$ & $4(1.1)$ & $8(2.1)$ & $8(2.1)$ & $2(0.5)$ \\
\hline CN VII impairment & $5(1.3)$ & $5(1.3)$ & $11(2.9)$ & $29(7.7)$ \\
\hline CN V impairment & $15(4.0)$ & $24(6.3)$ & $31(8.2)$ & $37(9.8)$ \\
\hline other & $3(0.8)$ & $11(2.9)$ & $14(3.7)$ & $14(3.7)$ \\
\hline no symptom & $8(2.1)$ & $0(0)$ & $8(2.1)$ & $6(1.6)$ \\
\hline incidental & $0(0)$ & $45(11.9)$ & $0(0)$ & $0(0)$ \\
\hline
\end{tabular}

intracanalicular (T1) tumors were excluded. The maximum anteroposterior extrameatal diameter of the tumors ranged from 4.9 to $33.5 \mathrm{~mm}$ (mean $15 \pm 6.7 \mathrm{~mm}$ ). The VS maximum latero-lateral extrameatal diameter ranged from 1.5 to $24.8 \mathrm{~mm}$ (mean $11.6 \pm 5.7 \mathrm{~mm}$ ). The VS maximum craniocaudal extrameatal diameter ranged from 3 to $30.3 \mathrm{~mm}$ (mean $12.9 \pm 12.2$ ). The maximum diameter of the internal acoustic meatus (IAM) ipsilateral to the VS ranged from 4.8 to $20 \mathrm{~mm}$ (mean $10.2 \pm 2.3 \mathrm{~mm}$ ) and that of the contralateral ranged from 4 to $12.5 \mathrm{~mm}$ (mean $7.9 \pm 1.6 \mathrm{~mm}$ ). The length of the internal acoustic canal (IAC) ranged from 7 to $19 \mathrm{~mm}$ (mean $12.1 \pm 6.3 \mathrm{~mm}$ ) and that of the VS intracanalicular portion ranged from 0.1 to $19 \mathrm{~mm}$ (mean $8.1 \pm 3.1 \mathrm{~mm}$ ). The distance between the lateral end of the VS intracanalicular portion and the fundus of the IAC ranged from 0 to $13.4 \mathrm{~mm}$ (mean $3.9 \pm$ $2.8 \mathrm{~mm}$ ). The minimum distance between the VS and the cochlea ranged from 0 to $9.4 \mathrm{~mm}$ (mean $2.2 \pm 1.9 \mathrm{~mm}$ ).

TABLE 2: Time from onset of signs or symptoms to VS diagnosis

\begin{tabular}{lcccc}
\hline \multicolumn{1}{c}{ Sign/Symptom } & $\begin{array}{c}\text { Mean (SD) } \\
(\mathrm{mos})\end{array}$ & $\begin{array}{c}\text { Median } \\
(\mathrm{mos})\end{array}$ & $\begin{array}{c}\text { Min } \\
(\mathrm{wks})\end{array}$ & $\begin{array}{c}\text { Max } \\
(\mathrm{yrs})\end{array}$ \\
\hline hearing loss & $30.5(46.1)$ & 21 & $<1$ & $30^{*}$ \\
tinnitus & $26.4(38.7)$ & 12 & $<1$ & $20^{*}$ \\
vertigo & $17.4(26.0)$ & 6 & $<1$ & 10 \\
disequilibrium & $20.2(54.8)$ & 12 & 2 & $30^{*}$ \\
lat headache & $21.7(58.6)$ & 5 & 2 & $20^{*}$ \\
Adams triad & $3.2(3.9)$ & 2 & $<1$ & 1 \\
CN VII impairment & $16.0(24.1)$ & 6 & 2 & 7 \\
CN V impairment & $10.8(14.4)$ & 6 & 2 & 5 \\
other & $1.8(4.0)$ & 0.2 & $<1$ & 2 \\
\hline
\end{tabular}

* $5,3,1$, and 1 patients complained of hearing loss, tinnitus, balance disorders, and ipsilateral ear pain, respectively, for more than 10 years.

\section{Environmental Risk Factors for Developing VS}

In the present series, 121 patients (32\%) reported that they had lived or worked in an extremely noisy environment for at least 20 years before the VS diagnosis.

Forty-two patients in our study reported having used mobile phones for $>2$ hours daily for more than 10 years before the VS diagnosis. On average, patients in this group used mobile phones 3.7 hours per day (median 3.5 hours per day, range $2-8$ hours per day). Patients with mobile phone use as a candidate risk factor for VS were younger (mean $50.9 \pm 12.6$ years, median 54 years) than those without a history of mobile phone use (mean $60.1 \pm$ 12.0 years, median 62 years).

The Mann-Whitney U-test was used to determine if there were statistically significant differences in mobile phone use between the 2 groups. Patients having mobile phone use as a risk factor (mean rank $=119.89$ ) were significantly younger than patients not having this risk factor $($ mean rank $=198.74, \mathrm{U}=4132.5, \mathrm{z}=-4.400, \mathrm{p}<$ 0.001). A higher incidence of VS on the side of the ear used to talk over the phone was also found. Among the 23 patients presenting with VS on the right side, 2 used to hold the phone on the left side and 21 on the right side; of the 19 patients harboring a VS on the left side, 8 used to hold the phone on the right side and 11 on the left side $(p=0.001$, chi-square $=11.784 ; p=0.001,2$-sided Fisher exact test).

\section{Tumor Control}

Qualitative data at the last radiological follow-up were obtained in all 379 patients included in the study. Quantitative radiological data (measured using the GammaPlan software) was collected in 219 patients, and the mean length of follow-up was 68.3 months (maximum 156 months). In these patients, $82.7 \%$ of the VSs showed a reduction in volume on the images taken at the last follow-up; the mean tumor volume decreased from 1.97 to $1.28 \mathrm{~cm}^{3}$ (a mean relative reduction of $34.6 \%$ ), and the 


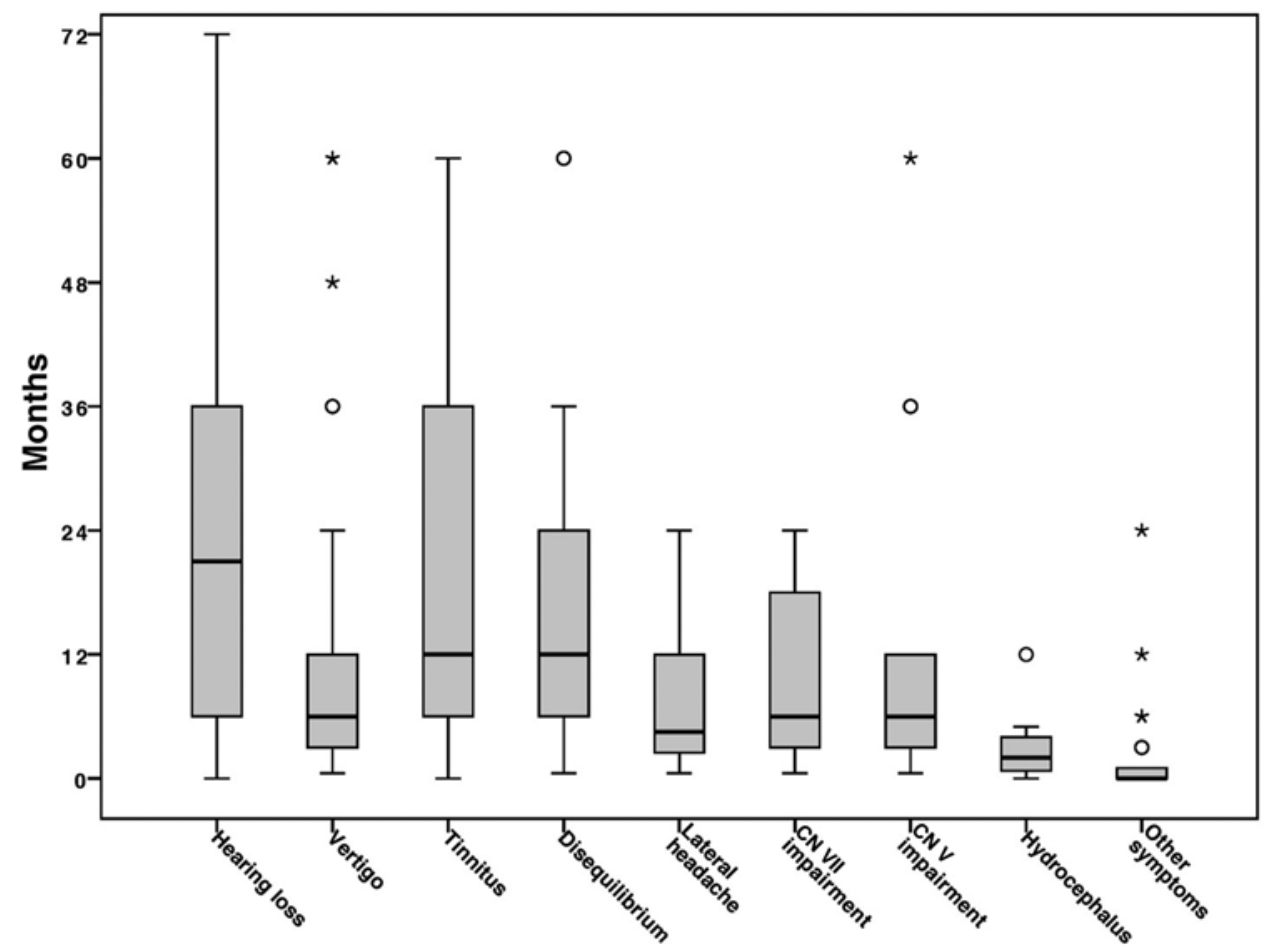

FIG. 2. Box plot depicting the time from onset of signs or symptoms to diagnosis. The black horizontal line in the boxes represents the median time (in months), and the gray box represents the range between the 25 th and 75 th percentiles.

mean maximum diameter decreased from 18.4 to 15.3 $\mathrm{mm}$. In the group in which initial GKRS treatment had failed, the mean volume increase at the time of retreatment was 323\% of the initial pre-GKRS volume. Table 6 reports the morphometric data for the different VS Samii stages at the last radiological follow-up.

Figure $3 \mathrm{~A}$ shows the distribution of the variation in VS volume after GKRS. A Kaplan-Meier plot of "retreatment-free" survival is shown in Fig. 3B.

Tumor control was achieved in $97.1 \%$ of the cases. In 11 patients (2.9\%), GKRS failed to control the tumor, and $3(0.8 \%)$ of these patients underwent a GKRS retreatment, and 8 (2.1\%) underwent microsurgical resection.

\section{Changes in Signs and Symptoms After GKRS}

Data indicating the changes in signs or symptoms after GKRS are reported in Table 7 and in Fig. 4.

\section{TABLE 3: Hearing function defined by GR class at the time of GKRS*}

\begin{tabular}{clcc}
\hline \multirow{2}{*}{ GR Class } & \multicolumn{2}{c}{ Age at GKRS (yrs) } & \\
\cline { 2 - 3 } & Mean (SD) & Median (range) & No. of Patients (\%) \\
\hline I & $50.7(12.9)$ & $52(24-77)$ & $83(21.9)$ \\
II & $57.5(11.3)$ & $59(23-81)$ & $104(27.4)$ \\
III & $62.6(11.0)$ & $64(27-85)$ & $128(33.8)$ \\
IV & $64.3(11.3)$ & $65(34-85)$ & $34(9.0)$ \\
V & $66.6(8.1)$ & $68(49-85)$ & $30(7.9)$ \\
\hline
\end{tabular}

\footnotetext{
* Of all patients, 187 (49.3\%) were in GR Classes I and II (serviceable
} hearing) and 192 (50.7\%) in Classes III-V (nonserviceable hearing).
Facial Neuropathy. Twenty-nine (7.7\%) patients had facial nerve (CN VII) impairment at the time of GKRS, and $22(75.9 \%)$ of them had completely recovered from this deficit by the last follow-up.

Facial nerve dysfunction occurred in $11(2.9 \%)$ patients after GKRS; in 2 cases, a worsening of a preexisting deficit was recorded, while 9 patients experienced a de novo CN VII impairment. At the last follow-up, only $4(1.1 \%)$ patients had permanent new or worsened facial nerve impairment.

Trigeminal Neuropathy. Trigeminal neuropathy was defined as any temporary or permanent, subjective or objective decrease in facial sensation, or as development of new pain within the ipsilateral trigeminal nerve $(\mathrm{CN} \mathrm{V})$ distribution. The trigeminal branches most frequently affected were both V2 and V3. Thirty-seven $(9.8 \%)$ patients had CN V impairment when GKRS was performed; 20 $(54.1 \%)$ of them had recovered by the last follow-up. A new onset or worsening of preexisting trigeminal nerve impairment occurred in $26(6.9 \%)$ patients after GKRS; 5 patients had already been affected prior to GKRS, and 21 patients experienced this impairment for the first time. At the last follow-up, only 7 (1.8\%) patients had a new or worsened CN V impairment. Trigeminal neuralgia was more likely to subside (in $88.9 \%$ of cases) than facial hypoesthesia (64.7\%).

Vertigo and Disequilibrium. Seventy-two (19.0\%) patients had vertigo at the time of GKRS. Of these, 45 (62.5\%) had completely recovered by the last follow-up. Thirty patients $(7.9 \%)$ experienced either a new onset of vertigo (22 patients) or a worsening ( 8 patients) after 
N. Boari et al.
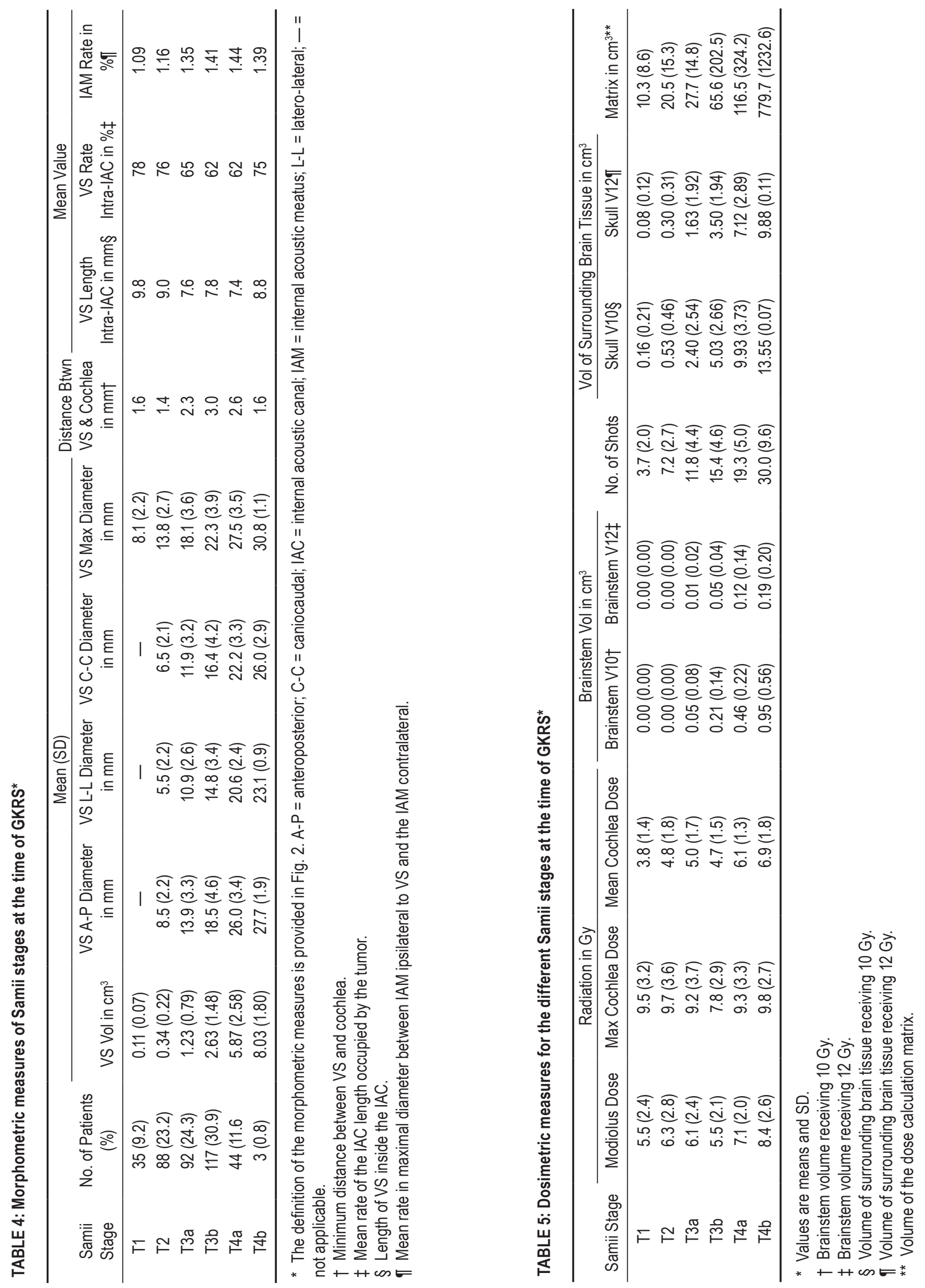


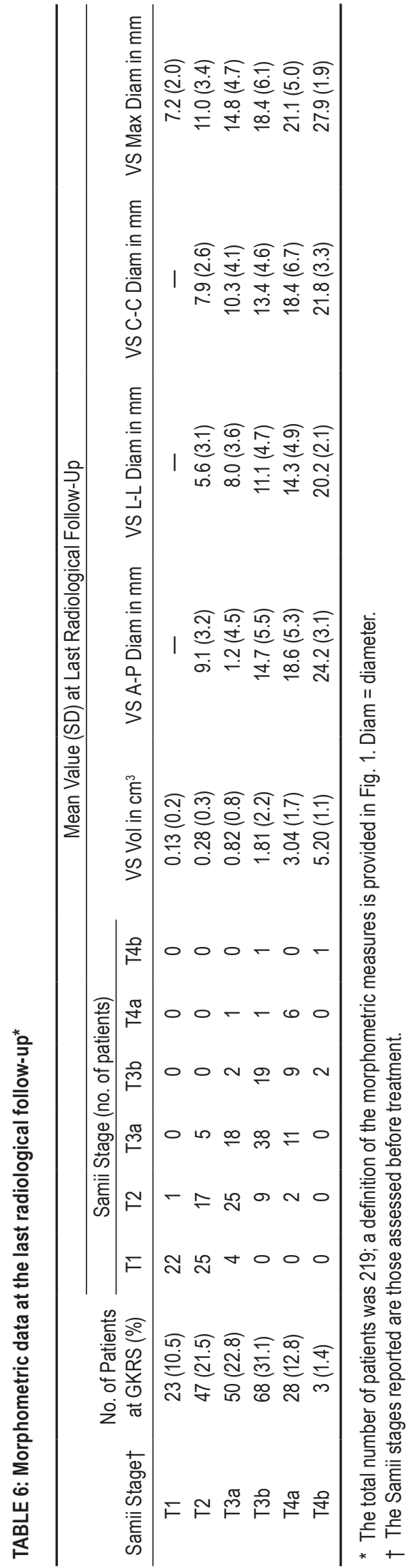

GKRS, and 22 (73.3\%) had recovered from vertigo by the last follow-up.

Of 102 patients reporting disequilibrium, 51 (50\%) recovered after GKRS. In 30 patients (7.9\%), either a new onset (23 patients) or a worsening (7 patients) of balance disorders was observed after GKRS; 18 patients $(60 \%)$ had completely recovered by the time of follow-up. These data show that patients with a de novo balance disorder were more likely to recover $(69.6 \%)$ than those experiencing a deterioration of a preexisting one (28.6\%).

Tinnitus. One hundred two patients $(39.6 \%)$ reported tinnitus at the time of GKRS, and only $20(13.3 \%)$ recovered from the condition after the treatment. In 18 cases (4.7\%), tinnitus worsened after radiosurgery; of these patients, only $6(33.3 \%)$ had completely recovered by the last follow-up.

Lateral Headache. Ten patients (2.6\%) reported either headache or pain around the ear on the same side of the VS (defined as "lateral headache") before treatment; of these, $4(40 \%)$ recovered from these symptoms after GKRS. Eleven patients (2.9\%) experienced a worsening or a new onset of this symptom, and 4 of these (36.4\%) were free of it at the last follow-up.

Hydrocephalus. An enlargement of the ventricular system was detected in 20 patients (5.3\%) at the radiological follow-up. At the time of the radiological diagnosis of hydrocephalus, only 4 patients $(1.1 \%)$ were symptomatic, and all 20 patients had communicating hydrocephalus. The Samii stage at GKRS was T4b in 1 patient, T4a in 9, $\mathrm{T} 3 \mathrm{~b}$ in $6, \mathrm{~T} 3 \mathrm{a}$ in 3 , and T2 in 1 . The mean tumor volume at GKRS was $4.44 \pm 2.9 \mathrm{~cm}^{3}$ (median $4 \mathrm{~cm}^{3}$, range 0.63-9.9 $\mathrm{cm}^{3}$ ). The mean maximum (intra- and extracanalicular) axial diameter of the VS was $27.5 \pm 4.9 \mathrm{~mm}$ (range 17-33 $\mathrm{mm}$ ); it was $<25 \mathrm{~mm}$ in only 3 cases.

\section{Timing of Complications}

Table 8 shows the lengths of time from GKRS to new onset, worsening, or resolution of signs or symptoms. In most cases, the new onset or worsening of preexisting signs or symptoms or their resolution occurred in the first 24 months after the treatment. The median time of worsening of a preexisting symptom (between 6 and 18 months in most cases) was usually longer than the time of a de novo occurrence (first 6-12 months in most cases). No new event was observed after the 96 months following GKRS.

\section{Hearing Preservation}

Ninety-six patients who had useful hearing (GR Class I in 48 and GR Class II in 48) at the time of GKRS and who had undergone pre- and regular postradiosurgical audiometric testing were analyzed. At the last audiometric follow-up, the overall rate of functional hearing preservation was $49.0 \%$ (with a mean follow-up of 59.9 months); in patients with GR Class I function, it increased to $70.8 \%$ (mean follow-up 63.7 months). However, if only patients classified as having GR Class II hearing at the time of GKRS were considered, it dropped to $27.1 \%$ (with a mean follow-up of 56.1 months). 


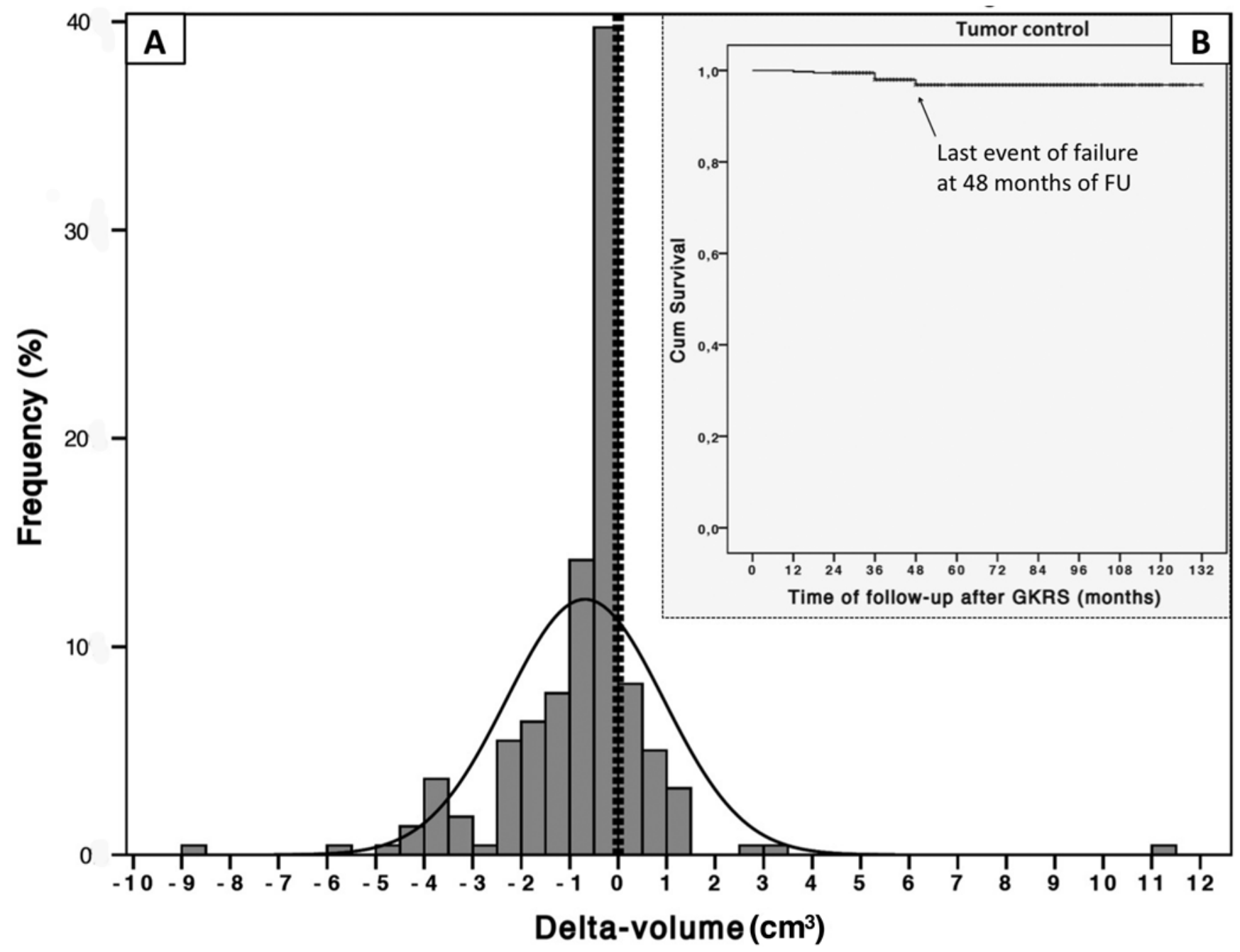

FIG. 3. Changes in tumor volume and tumor control after GKRS treatment. A: Histogram depicting the difference in tumor volume (in $\mathrm{cm}^{3}$ ) between before GKRS and at last radiological follow-up. The bolded, dashed vertical line represents the VS volume at the time of GKRS. One case of considerable volume growth is shown; this patient exhibited an expansion of the cystic component and eventually underwent resection. B: Kaplan-Meier plot of "retreatment-free" survival at follow-up; no events of treatment failure were recorded after 48 months of follow-up. Cum = cumulative; FU = follow-up.

Kaplan-Meier plots illustrating functional hearing preservation (Fig. 5A) and GR class preservation (Fig. 5B) at follow-up in the different GR groups are shown. At 1-, 3-, and 5-year follow-ups, the functional hearing preservation was $87.8 \%, 77.6 \%$, and $75.5 \%$, respectively, in GR Class I patients, and $68.1 \%, 31.9 \%$, and $21.3 \%$, respectively, in GR Class II patients.

In a multivariate analysis using the Cox regressionBreslow method for ties, the only variable identified as statistically significant for GR class loss and functional hearing loss at last follow-up was the age of the patient at $\operatorname{GKRS}(\mathrm{p}=0.023$ and $\mathrm{p}=0.014$, respectively).

Patients treated at an age $\geq 55$ years had a higher probability of losing serviceable hearing (OR 5.37, 95\% CI 2.2-12.9; relative risk 2.49, 95\% CI 1.5-4.1): $30.8 \%$ of the patients $\geq 55$ years old retained a functional hearing at the last follow-up versus $70.5 \%$ of those $<55$ years old. The hearing preservation distributions (Fig. 5C) for the 2 age groups were significantly different in log-rank (chi-square $=17.986, \mathrm{p}<0.001)$, Breslow (chi-square $=$ $16.745, \mathrm{p}<0.001$ ), and Tarone-Ware (chi-square $=17.561$, $\mathrm{p}<0.001)$ tests.

Considering only GR Class I patients, preservation of functional hearing was $92.6 \%$ in patients $<55$ years old at GKRS and $42.9 \%$ in patients presenting at an older age; an age $\geq 55$ years was thus associated with a higher risk of serviceable hearing loss at follow-up (OR 16.67, 95\% CI 3.1-89.4; relative risk 5.15, 95\% CI 1.4-18.9). The survival distributions (Fig. 5D) for the 2 age groups were significantly different in log-rank (chi-square $=13.137, \mathrm{p}$ $<0.001$ ), Breslow (chi-square $=12.106, \mathrm{p}=0.001$ ), and Tarone-Ware (chi-square $=12.708, \mathrm{p}<0.001)$ tests.

In our series, the mean PTA in the nonaffected (control) ear at the time of GKRS was $17.7 \mathrm{~dB}$. The mean PTA loss per year after GKRS was $3.32 \mathrm{~dB} /$ year on the treated side, and $0.69 \mathrm{~dB} /$ year on the contralateral side. In patients whose hearing was classified as GR I at the time of GKRS, the mean PTA loss per year was $2.6 \mathrm{~dB} /$ 
Gamma Knife radiosurgery for VS

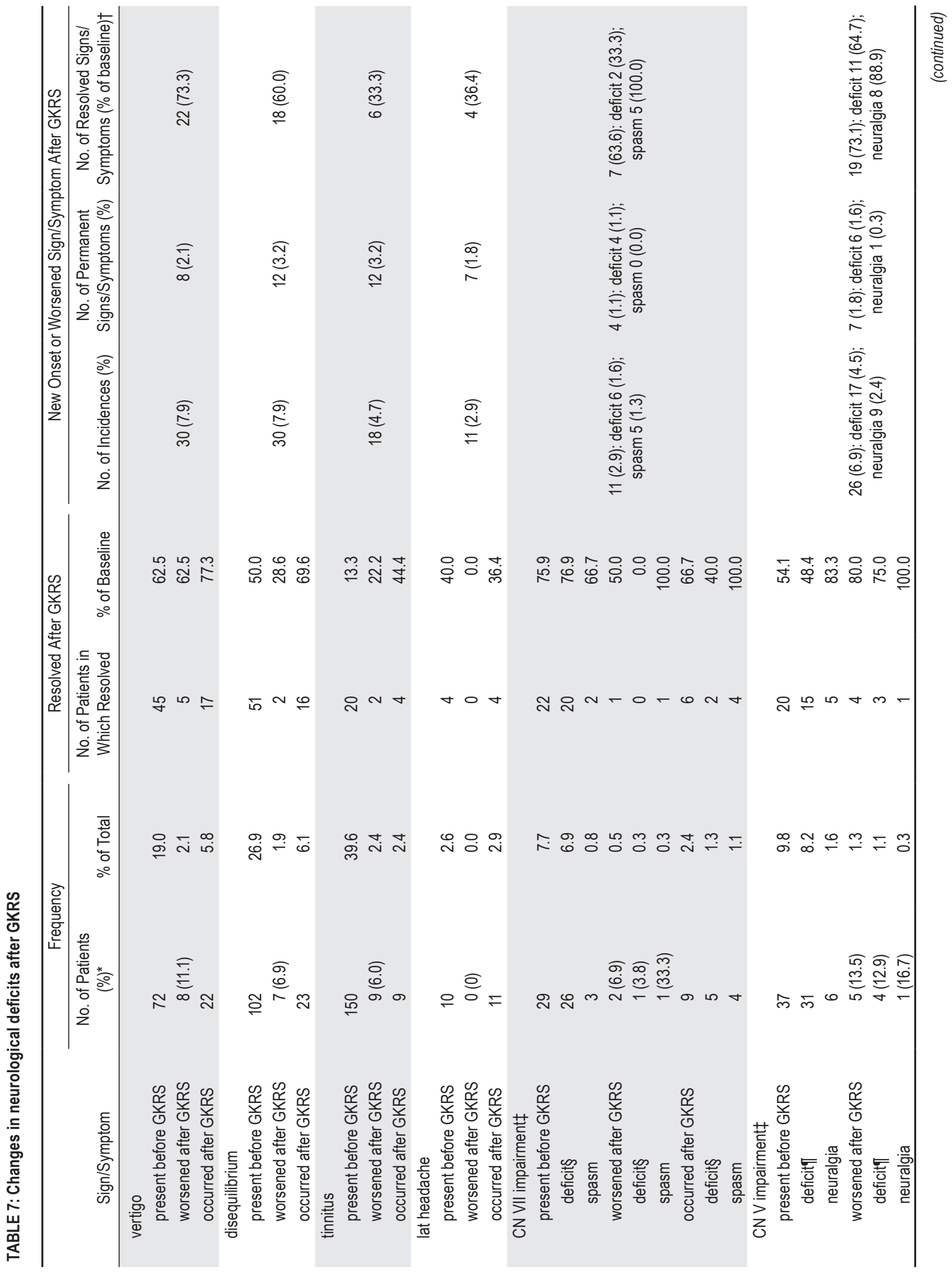


year $(0.66 \mathrm{~dB} /$ year in the contralateral ear). The PTA loss increased to $4.04 \mathrm{~dB} /$ year $(0.73 \mathrm{~dB} /$ year in the contralateral ear) when patients classified as GR II at GKRS were considered (Fig. 6). The mean PTA loss was higher in the first 2 years after treatment $(7.03 \mathrm{~dB} /$ year $)$ than thereafter (2.39 dB/year); in particular, the PTA loss was highest in the first 12 months after GKRS. Considering only GR Class I patients, we noted a 10.11-dB PTA decrease in the 1st year after treatment and then a mean loss of $1.77 \mathrm{~dB} /$ year later on. In the GR Class II patients, we observed a mean loss of $11.22 \mathrm{~dB}$ in the 1st year after GKRS and a 3.24-dB/year loss thereafter.

\section{Statistical Analysis}

A summary of the results of the uni- and multivariate analyses is shown in Table 9.

\section{Discussion}

\section{Environmental Risk Factors for Developing VS}

Many possible risk factors for developing a VS have been suggested in the literature. To date, none of these factors has reached a significant level of supporting evidence.

Exposure to loud noise, either in the workplace or from loud music, has been associated with an increased risk of VS in 2 case-control studies. ${ }^{11,41}$ An association with the duration of exposure was observed in 1 study, in which those with $\geq 20$ years of occupational exposure had an over 10-fold increase in risk. ${ }^{40}$ Experimental studies of tissue injury and repair after acoustic trauma support the biological plausibility of this association. ${ }^{19,50}$ In the present series, 121 patients (32\%) reported to have lived or worked in an extremely noisy environment for at least 20 years before the VS diagnosis.

In May 2011, the International Agency for Research on Cancer classified radiofrequency electromagnetic fields as possibly carcinogenic to humans (Group 2B). This classification was based on limited epidemiological evidence for an increased risk of glioma and VS associated with exposure to wireless phones, on limited evidence in experimental animals, and on weak mechanistic support. ${ }^{1}$ In our study, 42 patients had used cellular phones > 2 hours daily for more than 10 years before the diagnosis of VS. These patients generally reported holding the phone with their dominant hand. Only a few reported using the nondominant hand, usually those who had to write while on the phone. Patients with use of mobile phones as a risk factor for VS were significantly and about 10 years younger than those without this risk factor. We also noted a higher incidence of VS on the side of the ear used during phone calls. These data are not conclusive and have to be confirmed in larger series and in prospective studies specifically aimed and designed to evaluate possible risk factors in developing VS.

\section{Signs and Symptoms}

The mean length of time from first onset of the presenting signs and symptoms of VS to eventual diagnosis was $31.6 \pm 50.9$ months (median 12 months). The onset 


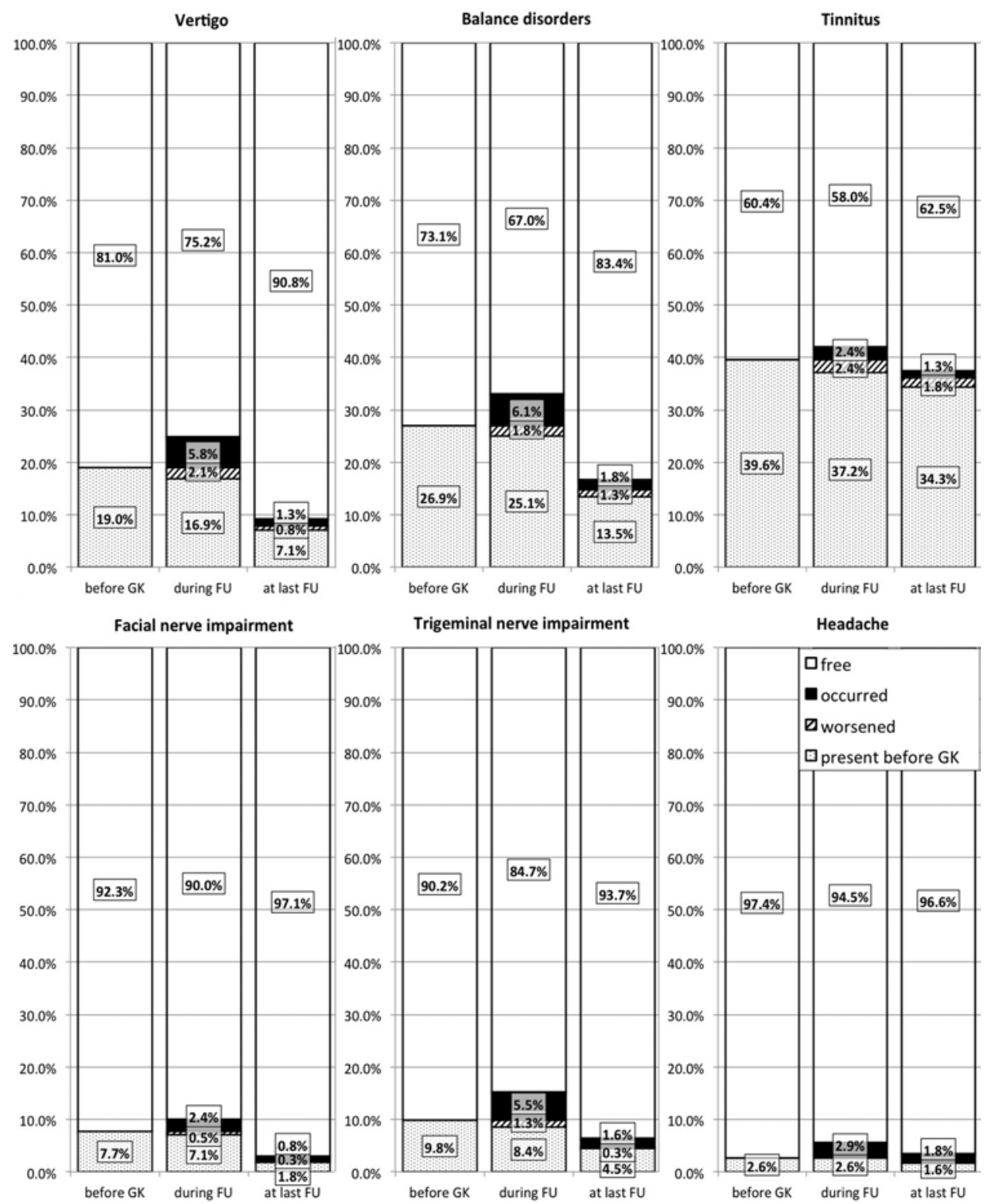

FIG. 4. Changes in neurological deficits after GKRS. The rates of patients "free from sign or symptom," with "sign or symptom occurred de novo," with "sign or symptom already present before radiosurgery," or with "sign or symptom worsened after the treatment" are reported for each sign or symptom at 3 different times: the day of the GKRS treatment (first bar), during follow-up (second bar), and at last clinical follow-up (third bar).

signs and symptoms were related to the impairment of the vestibulocochlear nerve in more than $80 \%$ of the cases. We believe that the long time interval between signs and symptoms and diagnosis may be mostly due to both patients and possibly caring physicians failing to recognize hearing loss and tinnitus as possible symptoms of VS.

The longest mean time interval between onset of signs and symptoms and diagnosis was indeed reported for hearing decline and tinnitus $(30.5 \pm 46.1$ and $26.4 \pm$ 38.7 months, respectively; the median time was 21 and 12 months, respectively). Also, the time interval from diagnosis to treatment was quite long (mean $11.1 \pm 26$ months, median 5 months), thus increasing the time interval from symptom onset to treatment, whose respective mean and median were $41.0 \pm 20.1$ months and 28 months. We ar- gue that this further delay between diagnosis and treatment could be related to the inconsistent indications for the recommended treatment provided by different physicians, including general practitioners, otolaryngologists, and neurosurgeons. These often confounding suggestions cause patients to seek multiple consultations and auto-referrals before choosing a treatment.

\section{Tumor Control}

Tumor swelling in the first $1-3$ years after GKRS is quite common and is usually associated with transient loss of central enhancement on MRI scans. ${ }^{22,38,47}$ In a series of 208 patients, $30 \mathrm{VSs}(14 \%)$ enlarged at least $2 \mathrm{~mm}$ at a median time of 9 months (5-60 months); the median 


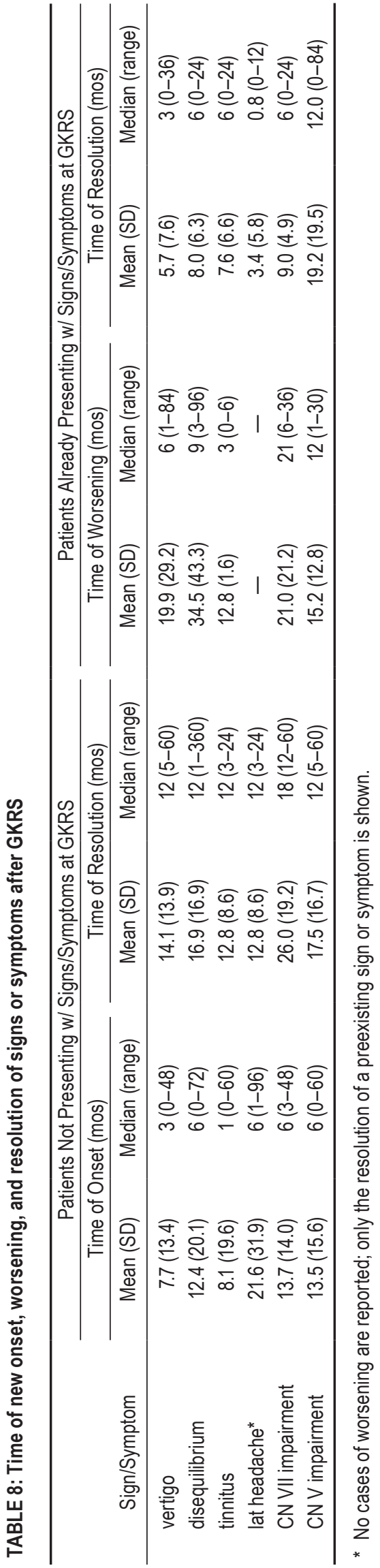

volume increase was $75 \%$, but only in 2 cases $(0.97 \%)$ was surgical treatment eventually needed..$^{38}$ In a study of 332 patients, tumor swelling at 6 months was observed in $54 \%$ of the patients, and in $27 \%$ of these patients the swelling ranged from $30 \%$ to $200 \%$ of the initial volume. ${ }^{9}$ At 3 years, $22 \%$ of the VSs were larger than at the time of the GKRS but stable: only 16 patients (4.8\%) ultimately underwent surgery. ${ }^{9}$

We defined tumor control as no need for further treatments. Eleven patients (2.9\%) in our series eventually underwent further treatment; in this group, the mean volumetric increment at the time of retreatment was 323\% relative to the initial pre-GKRS volume. No predictive model was identified for the failure of GKRS treatment, and we believe that this lack of a model might be due to the low number of events (11 cases), precluding identification of significant correlations in the statistical analysis.

In a systematic analysis of the literature, the mean rate of tumor control was reported to be $94 \% .{ }^{67}$ To better define the concept of treatment failure, it is important to be acquainted with the 3 patterns of radiosurgically treated VS originally described by Pollock and colleagues: transient tumor growth in 15\%-30\% of cases, initial growth followed by stabilization at a higher tumor volume in the long term in 5\%-10\%, and progressive growth (treatment failure) in $<5 \%{ }^{38,39,47}$ Since the incidence of tumor growth after GKRS (mainly in the first 3-13 months) has a reported rate ranging from $10 \%$ to $50 \%$ (depending on the variable measured, that is, volume or diameter), we agree that a reasonable definition of treatment failure is that provided by Delsanti et al., as "a continuous growth of the VS for more than 3 years after radiosurgery." 9 In our series, no instances of treatment failure were observed later than 4 years after GKRS (Fig. 3B).

\section{Complications}

Facial Nerve Impairment. Sparing facial nerve function is one of the most important goals in VS therapy. In the early age of GKRS, the rate of facial nerve dysfunction was $30 \%$ to $40 \% ; 36$ this rate has been continuously reduced to $<2 \%$. $12,27,63,66$ In a 2009 meta-analysis of 2204 patients treated with GKRS for VS, a significant facial nerve deficit (HB grade $\geq$ III) was observed in $3.8 \%$ of cases ${ }^{69} \mathrm{In}$ a large series, reported in the last decade, facial nerve impairment was reported between $0 \%$ and $2.7 \%$. $^{6,7,13,20,25,28,29,42,66}$ In our series, we recorded overall (new-onset/worsening) permanent facial nerve deficit ( $\mathrm{HB}$ grade $>\mathrm{I}$ ) in $1.1 \%$ of the patients, while the rate of new CN VII impairment in the patients not previously affected was $0.8 \%$.

In the logistic regression analysis, a higher $\mathrm{HB}$ class at GKRS was found to significantly correlate with a higher probability of permanent facial nerve impairment $(\mathrm{p}=0.006)$. It was not possible to calculate a predictive model for the occurrence of facial nerve impairment. Our results, using current dosimetric parameters (that is, prescription doses of $\leq 13 \mathrm{~Gy}$ ), confirm that the risk of a new occurrence of facial nerve impairment is very low.

Trigeminal Impairment. A 2009 meta-analysis of 5631 patients by Sughrue and colleagues reported a 2.3\% rate of new trigeminal neuropathies after GKRS and that 

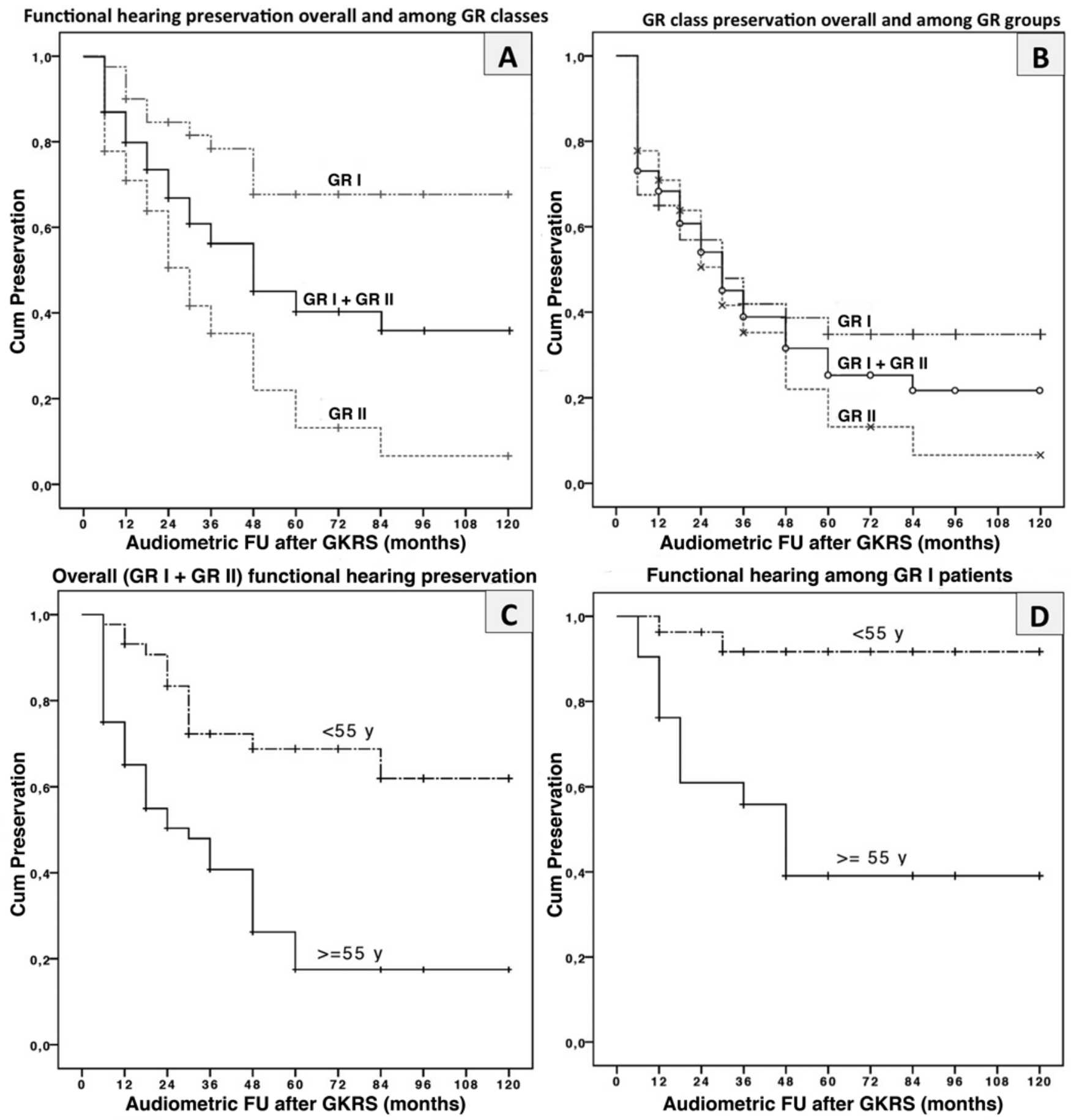

FIG. 5. Preservation of functional hearing after GKRS. A: Kaplan-Meier plot illustrating functional hearing preservation after GKRS at follow-up: overall (GR Class I + GR Class II patients), in GR Class I patients, and in GR Class II patients. B: Kaplan-Meier plot showing GR class preservation after GKRS at follow-up: overall (GR Class I + GR Class II patients), in GR Class I patients, and in GR Class II patients. C: Kaplan-Meier plot showing overall functional hearing preservation in patients presenting with less then 55 years at GKRS and in older patients. D: Kaplan-Meier plot of GR Class I patients' functional hearing preservation in those presenting at age $<55$ years at GKRS and in those treated at an older age.

the risk of trigeminal impairment after GKRS significantly decreases when prescription doses of $\leq 13 \mathrm{~Gy}$ are used $(3.15 \%$ new trigeminal neuropathies in the $>13$ Gy group vs $1.63 \%$ in the $<13$ Gy group).$^{59}$ In our study, we observed a $1.8 \%$ rate of permanent CN V impairment. A statistical analysis showed that the volume of the brainstem receiving 10 Gy or more (that is, a brainstem V10) correlated with the probability of developing trigeminal nerve dysfunction $(\mathrm{p}=0.016)$ and with a lower probability of resolving this symptom at follow-up $(\mathrm{p}=0.001)$. 

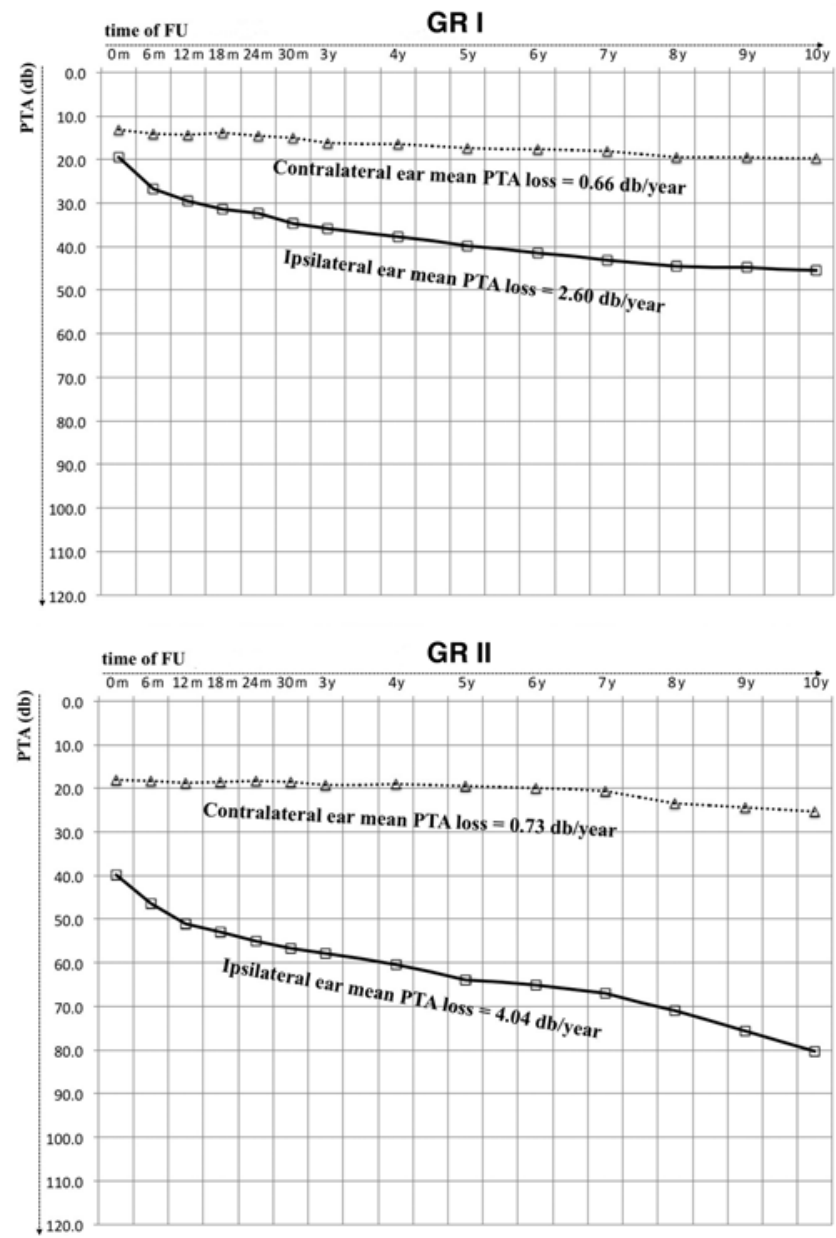

Fig. 6. Mean variation of PTA in the contra- and ipsilateral ear during sequential follow-up exams after GKRS. The variation in PTA is shown for patients whose hearing was classified as GR Class I (upper) and GR Class II (lower) at the time when GKRS was performed. $\mathrm{m}=$ months; $y=$ years.

Vertigo and Imbalance. In the meta-analysis by Sughrue et al., incidence of vertigo or imbalance after GKRS was reported to be $1.5 \%$ (1.1\% in the $\leq 13 \mathrm{~Gy}$ group and $1.8 \%$ in the $>13$ Gy group). ${ }^{59}$ In our series, we observed a $2.1 \%$ and $3.2 \%$ rate of permanent vertigo and disequilibrium, respectively. When considering only the new-onset cases, we observed $1.3 \%$ and $1.8 \%$ for permanent vertigo and permanent disequilibrium, respectively. In the logistic regression analysis, we found a higher probability for women to develop vertigo $(p=0.012)$ or imbalance $(\mathrm{p}=0.003)$; a VS larger than $25 \mathrm{~mm}$ in maximum axial diameter was also correlated with a higher probability of balance complications $(\mathrm{p}=0.041)$ (Table 9). A higher probability of persistent vertigo after GKRS was correlated with the VS anteroposterior diameter $(\mathrm{p}=$ $0.010)$ and the diameter of IAM ipsilateral to the VS (p $=0.034$ ).

Tinnitus. The meta-analysis by Sughrue and colleagues reported a $1.7 \%$ incidence of tinnitus in patients receiving less than $13 \mathrm{~Gy}$ as the marginal dose. ${ }^{59}$

In our study, we observed permanent tinnitus after
GKRS in $3.2 \%$ of the cases. The rate of recovery of a preexisting tinnitus after GKRS was low (20\%). Statistical analysis showed a higher probability of incidence of tinnitus after GKRS in patients reporting an intensive use of mobile phones before the VS diagnosis ( $\geq 2$ hours daily, for more than 10 years) $(p=0.036)$. In addition, the length of the VS inside the IAC was found as a predictor for both occurrence $(p=0.047)$ and persistence of tinnitus after GKRS $(\mathrm{p}=0.029)$.

Hydrocephalus. In the same meta-analysis, ${ }^{59}$ the reported incidence of hydrocephalus was $0.85 \%$. In individual series, higher incidences have been reported (that is, in $4 \%$ of the cases). ${ }^{32,47,48}$

In our series, we observed a significant enlargement of the ventricular system, detected by radiological methods, in 20 patients $(5.3 \%)$ after GKRS. Only 4 patients $(1.05 \%)$ were reporting hydrocephalus-associated symptoms at the time of its radiological diagnosis, but we opted for a proactive treatment (that is, a ventriculoperitoneal shunt) in 16 out of 20 cases (80\%). In the other 4 cases, considering the mild enlargement of the ventricular system not associated with any clinical sign or symptom, we used a "wait-and-scan" strategy; patients' neurological status and size of the ventricular system both remained stable at follow-ups.

Other Complications. The risk of CN VI palsy is reported to be approximately $0.3 \%$ in the literature, while that of CN XII neuropathy is $0.08 \% .{ }^{47}$ We found no evidence for these complications in our series.

\section{Hearing Preservation After GKRS}

A systematic review of the literature by Yang et al. reported that among 4234 patients (followed-up on average 44.4 months, median 35 months) overall preservation of functional hearing was $51 \%$ (60.5\% in patients receiving $\leq$ 13 Gy and $50.4 \%$ in patients receiving $>13 \mathrm{~Gy}$ ). ${ }^{68} \mathrm{In}$ a series of 117 patients (median follow-up 38 months and mean marginal dose $12.4 \mathrm{~Gy}$ ), hearing preservation was achieved in $55 \%$ of the patients at 3 years and in $34 \%$ at 8 years. ${ }^{21}$ Patients in a series from Carlson et al. reported a serviceable hearing preservation of 55\% at 3 years and $23 \%$ at 10 years. ${ }^{4}$ At the last audiometric follow-up in our series, the overall rate of preservation of functional hearing was 49\% (the mean follow-up was 59.9 months). In GR I patients, this rate increased to $70.8 \%$ (39.6\% were still in GR I class at the last follow-up; the mean follow-up was 63.7 months), and it dropped to $27.1 \%$ (at a mean follow-up of 56.1 months) when we considered only patients classified as GR II at the time when GKRS was performed.

If considering only GR I patients, functional hearing preservation increased up to $92.6 \%$ in patients who were $<55$ years old at the time of GKRS, while it was $42.9 \%$ in patients treated at an older age. In the multivariate analysis, the only variable found significant for "GR class loss" and "functional hearing loss" at last follow-up was the age of the patient at GKRS $(\mathrm{p}=0.023$ and $\mathrm{p}=$ 0.014 , respectively). A correlation between age and serviceable hearing preservation has also been reported by other authors. . $^{14,26,46,60}$

Among a subgroup of 80 patients in a series described 
Gamma Knife radiosurgery for VS

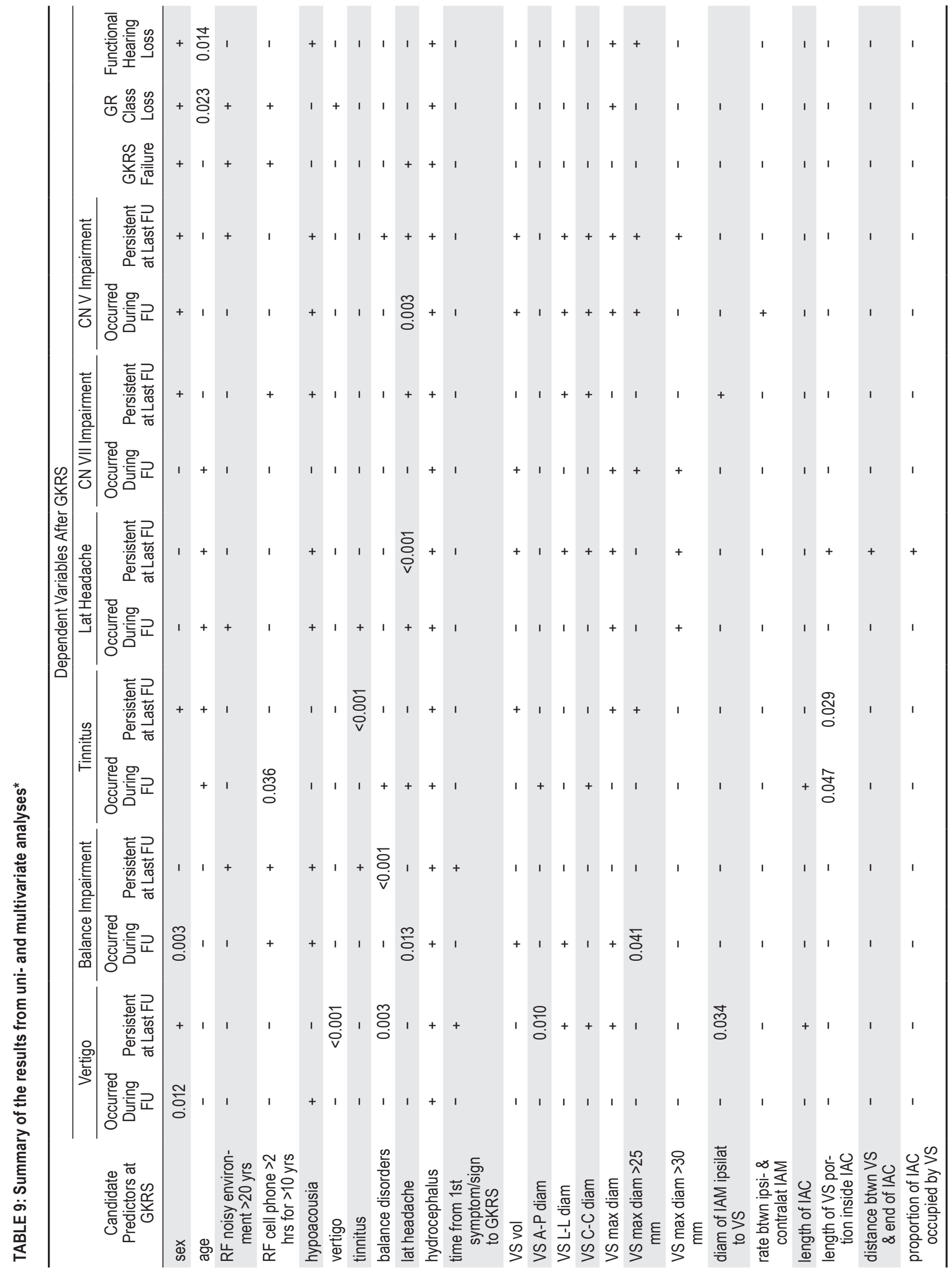


N. Boari et al.

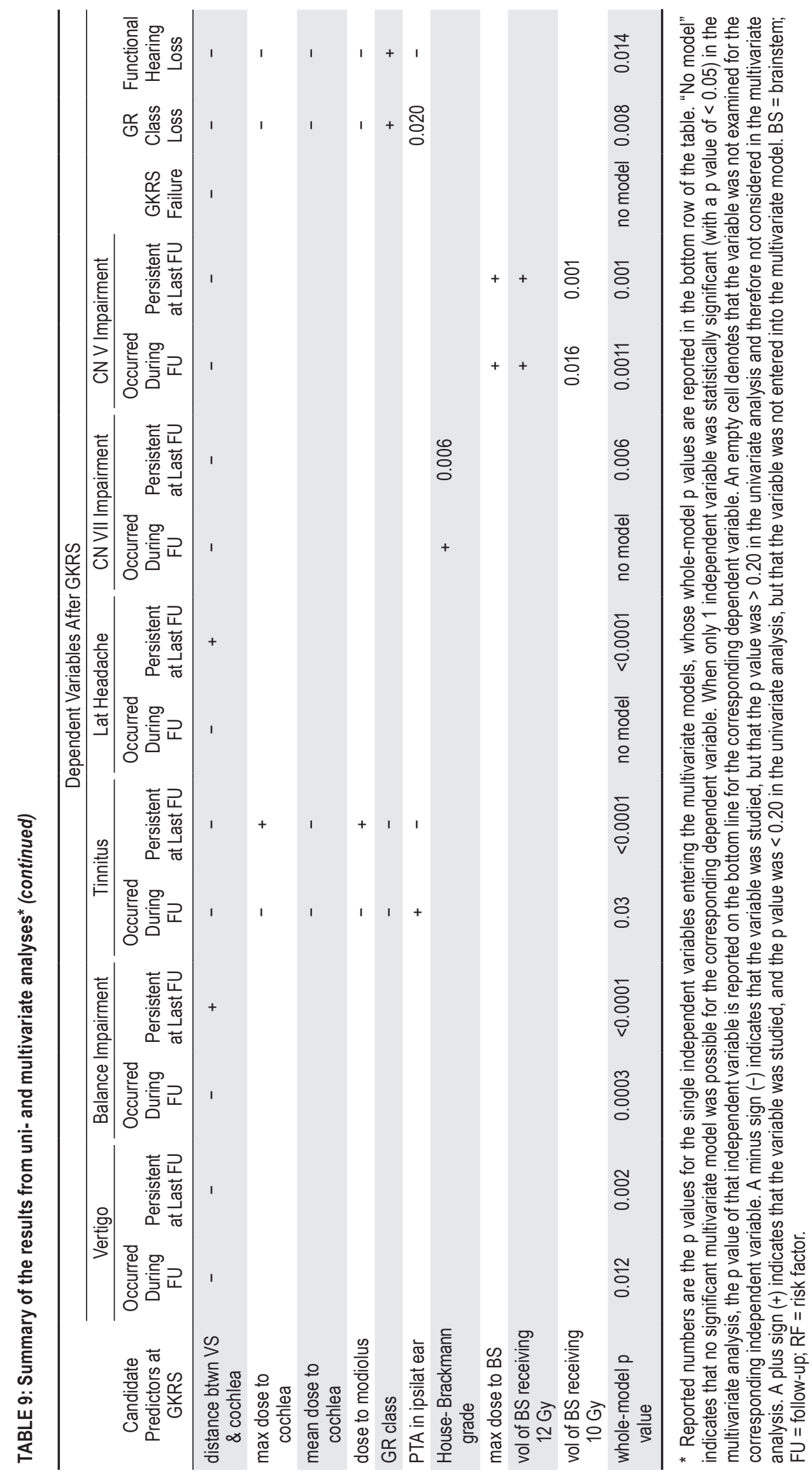


by Yomo et al., the mean annual rate of hearing decrease was reported as $5.86 \mathrm{~dB} /$ year in the first 2 years of follow-up and $1.86 \mathrm{~dB} /$ year thereafter. ${ }^{70}$ Taking into account all of the patients with functional hearing at GKRS, we found a mean PTA loss of $3.32 \mathrm{~dB} /$ year; the mean PTA loss was higher in the first 2 years after treatment $(7.03$ $\mathrm{dB} /$ year) than thereafter $(2.39 \mathrm{~dB} /$ year). In particular, we found the PTA loss to be the highest in the first 12 months after GKRS. If considering GR Class I patients only, we observed a 10.11-dB decrease in the 1st year after treatment and then a mean PTA loss of $1.77 \mathrm{~dB} /$ year later on; in the subgroup of GR Class II patients, we observed a mean loss of $11.22 \mathrm{~dB}$ in the 1st year after GKRS and a 3.24-dB/year loss thereafter.

Yomo et al. found a maximum cochlear dose of < 4 Gy as the sole prognostic factor for hearing preservation..$^{70}$ We could not identify any association of hearing preservation with the dose to the cochlea in our analysis.

We found that patients with hearing classified as GR Class I at the time of the GKRS had a lower PTA loss (2.60 vs $4.04 \mathrm{~dB}$ per year) and a much higher probability of having preserved functional hearing $(70.8 \%$ vs $27.1 \%)$ than those with hearing classified as GR Class II. In our series, the mean PTA in the nonaffected (control) ear at the time of GKRS was $17.7 \mathrm{~dB}$, and progressive hearing deterioration before treatment was reported as ranging between 3 and $13 \mathrm{~dB}$ of PTA per year. $3,18,30,33,37,45,56,61,62$ Therefore, it is reasonable to argue that a delay in VS treatment may increase the risk for loss of functional hearing.

\section{GKRS Versus Microsurgery}

According to the published literature, the rates of tumor control appear to be comparable between microsurgery and stereotactic radiosurgery for tumors $<3 \mathrm{~cm}$ in size,$^{53}$ but reported complications (including hearing loss) are significantly higher after microsurgery. In a microsurgical series, mortality rates ranged from $0 \%$ to $6 \%$ (mean $0.8 \%)^{35}$

McClelland et al. reported an $8.4 \%$ rate of surgical complications (including those due to infarction or hemorrhage).$^{31}$ The mean reported incidence of other complications in recent large microsurgical series are 8.2\% (2\%$15 \%)$ for CSF leaks, $2.8 \%(0 \%-8 \%)$ for meningitis, $3.1 \%$ $(0 \%-15 \%)$ for CN IX-XI deficits, and $17.7 \%(3 \%-35 \%)$ for balance problems..$^{35}$ A rate of $3.2 \%$ for hydrocephalus was also reported. ${ }^{31}$ Recent microsurgery series report rates of facial nerve preservation as ranging between $31 \%$ and $93 \% .{ }^{35}$ In a series of 110 patients described by Régis et al., a 55\% rate of newly developed trigeminal symptoms was reported. ${ }^{44}$ Samii and Matthies reported a trigeminal disturbance in $15.5 \%$ of 1000 patients, with the V2 most frequently affected. ${ }^{52}$ Régis et al. reported a $40 \%$ rate occurrence of tinnitus after surgery; they also showed that in those affected preoperatively, this symptom remained unchanged after the surgery in $67 \%$ of cases. ${ }^{44}$ Samii and Matthies reported a 35\% incidence of new onset tinnitus. ${ }^{52}$ Comparative studies showed a deterioration in quality of life in as high as 30\%-45\% of surgically treated patients. ${ }^{64}$ In microsurgical series of patients with certain tumors, functional hearing might be initially preserved in even $30 \%-60 \%$ of the patients. ${ }^{5,15}$ Chee et al. reported results from a 126-patient surgical series showing preservation of functional hearing of $34.1 \%$ of the patients immediately after retrosigmoid microsurgery. ${ }^{5}$ Nevertheless, they observed a progressive deterioration of hearing during follow-ups (mean 113.4 months); at 10 years of follow-up, $<25 \%$ of the patients still retained a serviceable hearing. Similarly, Shelton et al. reported a significant hearing deterioration, defined as a speech discrimination score or a PTA elevation of $>15 \mathrm{~dB}$ or a loss in speech discrimination score of $>20 \%$, in $56 \%$ of patients who underwent middle fossa surgery. ${ }^{55}$ Other authors have reported progressive hearing deterioration after successful microsurgery to preserve hearing; however these studies are limited by shorter follow-up and by a high percentage of patients being lost at follow-up. . $^{15,65}$

The aforementioned data confirmed that GKRS is superior to microsurgery in terms of complication rate, mortality rate, and costs, and achieved comparable results in terms of tumor control..$^{53}$

\section{GKRS Versus Wait-and-See Strategy}

Serial imaging analysis of 552 VSs (17\% intracanalicular and $29 \%$ cisternal VS; mean follow-up 3.6 years, range $1-15$ years) managed conservatively indicated that the tumors showed growth of $>2 \mathrm{~mm}$ at follow-up; ${ }^{57} 80$ patients $(14.5 \%)$ eventually underwent surgical or radiosurgical treatment because the conservative treatment had failed.

Several studies have reported that early proactive treatment increases the rate of hearing preservation compared with observation only. Indeed, before any treatment, spontaneous acute or progressive worsening of hearing is common. Many studies have reported the following degrees in PTA loss per year during the natural history of VS (losses are in dB/year): $13,{ }^{37} 9,{ }^{61} 6,{ }^{33} 5.1,{ }^{30} 3-6,{ }^{45} 4.2,{ }^{3}$ $3.5,{ }^{56} 2.9,{ }^{18}$ and $2.8 .^{62}$ In 2012, Yomo and colleagues reported hearing outcomes in a series of 154 patients conservatively monitored for $>6$ months and then treated radiosurgically; the mean annual hearing loss in these patients was $5.39 \mathrm{~dB} /$ year and $3.77 \mathrm{~dB} /$ year before and after GKRS, respectively. ${ }^{70}$ In a large series from Denmark of 932 VSs managed conservatively, ${ }^{58}$ functional hearing was preserved at the last follow-up (mean follow-up 4.2 years, range $0.5-21$ years) in $70.1 \%$ of 455 patients classified according to the scale of the American Academy of Otolaryngology-Head and Neck Surgery ${ }^{8}$ as Class A or B (equivalent to GR Classes I and II, respectively) at diagnosis. Among the patients with Class A functional hearing, $81 \%$ had retained functional hearing at the last follow-up (55\% were still in Class A).

In 2010, Régis et al. compared outcomes of the waitand-see strategy (47 patients) with GKRS treatment (34 patients). Among the patients in the wait-and-see group $74 \%$ had tumor growth requiring treatment, compared with 3\% in the GKRS group (with 43.8 months of mean follow-up); rates of hearing preservation at 5 years were $41 \%$ in the wait-and-see group and 64\% in GKRS group. The authors concluded that the wait-and-see strategy exposes the patient to elevated risks of tumor growth and degradation of hearing. ${ }^{43}$ 
According to the aforementioned reports and the results of hearing analysis in our series, the wait-and-see strategy would not be indicated for VS, especially in young individuals who have GR Class I hearing, and who represent a subset of patients in whom a proactive treatment should be strongly recommended.

\section{Malignant Transformation and Radiation-Induced Tumors}

The incidence of malignant transformation after GKRS is still very controversial, and it is used by some authors to argue against recommending GKRS in the treatment of VS. It would seem unacceptable to bear the potential risk of malignancy after irradiation of a benign lesion. ${ }^{47}$ According to a 2010 literature review by Demetriades et al., ${ }^{10}$ only 14 cases of malignant VS were reported worldwide; only 6 of these had been irradiated, and only 3 had histological confirmation of a previously benign lesion. A 2011 literature review reported 12 cases of radiosurgery-associated malignant tumors. ${ }^{54}$ Rowe et al. reported a single case of astrocytoma in a 30,000 patient-year follow-up study, with no findings of any excess incidence of cerebral malignancy ${ }^{49}$ Estimates of the incidence of radiosurgery-induced tumors range from $0-3$ per 200,000 patients according to Ganz ${ }^{16}$ to 1 per 1000 according to Niranjan et al. ${ }^{34}$ In our series, we observed no malignant transformation or radiation-induced tumors. In view of these results, and in agreement with other authors,${ }^{64}$ we consider the risk of death by radiationinduced tumors negligible when taking into account the possible fatal complications of microsurgery, whose rates are reported to be up to $6 \%$, with a mean rate of $0.5 \%$ at 3 months. ${ }^{2,35}$

\section{Limitations of the Study}

One limitation of the present study was that the audiometric and the quantitative radiological follow-ups were obtained in only 2 subgroups of patients, accounting for 153 and 219 patients, respectively, out of a total of 379 patients included in this study. Nevertheless, patients' compliance with all the suggested examinations at follow-ups was extremely variable, in particular for patients living very far from our center. This limitation cannot be easily overcome, even by scheduling all the follow-ups at hospital discharge.

Concerning our research into potential environmental risk factors, in particular the use of cellular phones, another limitation may be that the results were based on patients' recollections and may therefore be biased. As stated above, a prospective study may be needed to confirm our observations.

To account for the number of cases reported, the statistical analysis involved a large number of comparisons. This may have resulted in regression overfitting, which could limit the general applicability of the results of our study beyond the considered patient population. Although it should be noted that our multivariate models contained a limited number of variables, the overfitting could represent a possible limitation of the study.

Finally, the results of our study are not generalizable to NF2 patients, who represent a specific patient subgroup harboring VS; indications, timing, and outcomes of
GKRS in NF2 patients are different from those reported for GKRS of the sporadic form of VS.

\section{Conclusions}

Gamma Knife radiosurgery is a safe and effective treatment for VS, with control of these tumors achieved in $97.1 \%$ of cases and a very low morbidity rate. This radiosurgery method appears to be the best treatment for solitary VS $<30 \mathrm{~mm}$ in cisternal diameter. Younger GR Class I patients had a significantly higher probability of retaining functional hearing even at the 10 -year followup. Ideally, the times between symptom onset, diagnosis, and treatment should be shortened to achieve preservation of functional hearing. Young GR Class I patients therefore represent a subset of patients in whom a proactive treatment should be strongly recommended.

\section{Disclosure}

The authors report no conflict of interest concerning the material or methods used in this study or the findings specified in this paper.

Author contributions to the study and manuscript preparation include the following. Conception and design: Boari, Bailo, Franzin, del Vecchio. Acquisition of data: Bailo. Analysis and interpretation of data: Boari, Bailo, Gemma, del Vecchio, Mortini. Drafting the article: Boari, Bailo. Critically revising the article: Boari, Gagliardi, Franzin, Mortini. Reviewed submitted version of manuscript: Gagliardi, Franzin, Mortini. Approved the final version of the manuscript on behalf of all authors: Boari. Statistical analysis: Bailo, Gemma. Administrative/technical/material support: del Vecchio, Bolognesi, Picozzi, Mortini. Study supervision: Picozzi, Mortini.

\section{References}

1. Baan R, Grosse Y, Lauby-Secretan B, El Ghissassi F, Bouvard V, Benbrahim-Tallaa $\mathrm{L}$, et al: Carcinogenicity of radiofrequency electromagnetic fields. Lancet Oncol 12:624-626, 2011

2. Barker FG II, Carter BS, Ojemann RG, Jyung RW, Poe DS, McKenna MJ: Surgical excision of acoustic neuroma: patient outcome and provider caseload. Laryngoscope 113:13321343,2003

3. Bozorg Grayeli A, Kalamarides M, Ferrary E, Bouccara D, El Gharem H, Rey A, et al: Conservative management versus surgery for small vestibular schwannomas. Acta Otolaryngol 125:1063-1068, 2005

4. Carlson ML, Jacob JT, Pollock BE, Neff BA, Tombers NM, Driscoll CL, et al: Long-term hearing outcomes following stereotactic radiosurgery for vestibular schwannoma: patterns of hearing loss and variables influencing audiometric decline. Clinical article. J Neurosurg 118:579-587, 2013

5. Chee GH, Nedzelski JM, Rowed D: Acoustic neuroma surgery: the results of long-term hearing preservation. Otol Neurotol 24:672-676, 2003

6. Chopra R, Kondziolka D, Niranjan A, Lunsford LD, Flickinger JC: Long-term follow-up of acoustic schwannoma radiosurgery with marginal tumor doses of 12 to 13 Gy. Int J Radiat Oncol Biol Phys 68:845-851, 2007

7. Chung WY, Liu KD, Shiau CY, Wu HM, Wang LW, Guo WY, et al: Gamma knife surgery for vestibular schwannoma: 10year experience of 195 cases. J Neurosurg 102 Suppl:87-96, 2005

8. Committee on Hearing and Equilibrium: Committee on Hearing and Equilibrium guidelines for the evaluation of hearing preservation in acoustic neuroma (vestibular schwannoma). Otolaryngol Head Neck Surg 113:179-180, 1995 
9. Delsanti C, Roche PH, Thomassin JM, Régis J: Morphological changes of vestibular schwannomas after radiosurgical treatment: pitfalls and diagnosis of failure. Prog Neurol Surg 21:93-97, 2008

10. Demetriades AK, Saunders N, Rose P, Fisher C, Rowe J, Tranter R, et al: Malignant transformation of acoustic neuroma/vestibular schwannoma 10 years after gamma knife stereotactic radiosurgery. Skull Base 20:381-387, 2010

11. Edwards CG, Schwartzbaum JA, Lönn S, Ahlbom A, Feychting $\mathrm{M}$ : Exposure to loud noise and risk of acoustic neuroma. Am J Epidemiol 163:327-333, 2006

12. Flickinger JC, Kondziolka D, Niranjan A, Lunsford LD: Results of acoustic neuroma radiosurgery: an analysis of 5 years' experience using current methods. J Neurosurg 94:1-6, 2001

13. Flickinger JC, Kondziolka D, Niranjan A, Maitz A, Voynov G, Lunsford LD: Acoustic neuroma radiosurgery with marginal tumor doses of 12 to 13 Gy. Int J Radiat Oncol Biol Phys 60:225-230, 2004

14. Franzin A, Spatola G, Serra C, Picozzi P, Medone M, Milani D, et al: Evaluation of hearing function after Gamma Knife surgery of vestibular schwannomas. Neurosurg Focus 27(6):E3, 2009

15. Friedman RA, Kesser B, Brackmann DE, Fisher LM, Slattery WH, Hitselberger WE: Long-term hearing preservation after middle fossa removal of vestibular schwannoma. Otolaryngol Head Neck Surg 129:660-665, 2003

16. Ganz JC: Gamma knife radiosurgery and its possible relationship to malignancy: a review. J Neurosurg 97 (5 Suppl): 644-652, 2002

17. Gardner G, Robertson JH: Hearing preservation in unilateral acoustic neuroma surgery. Ann Otol Rhinol Laryngol 97:55-66, 1988

18. Hajioff D, Raut VV, Walsh RM, Bath AP, Bance ML, Guha A, et al: Conservative management of vestibular schwannomas: third review of a 10-year prospective study. Clin Otolaryngol 33:255-259, 2008

19. Hamernik RP, Turrentine G, Roberto M, Salvi R, Henderson D: Anatomical correlates of impulse noise-induced mechanical damage in the cochlea. Hear Res 13:229-247, 1984

20. Hasegawa T, Fujitani S, Katsumata S, Kida Y, Yoshimoto M, Koike J: Stereotactic radiosurgery for vestibular schwannomas: analysis of 317 patients followed more than 5 years. Neurosurgery $\mathbf{5 7 : 2 5 7 - 2 6 5 , 2 0 0 5}$

21. Hasegawa T, Kida Y, Kato T, Iizuka H, Yamamoto T: Factors associated with hearing preservation after Gamma Knife surgery for vestibular schwannomas in patients who retain serviceable hearing. Clinical article. J Neurosurg 115:10781086, 2011

22. Hasegawa T, Kida Y, Yoshimoto M, Koike J, Goto K: Evaluation of tumor expansion after stereotactic radiosurgery in patients harboring vestibular schwannomas. Neurosurgery 58:1119-1128, 2006

23. Hirsch A, Norén G, Anderson H: Audiologic findings after stereotactic radiosurgery in nine cases of acoustic neurinomas. Acta Otolaryngol 88:155-160, 1979

24. House JW, Brackmann DE: Facial nerve grading system. Otolaryngol Head Neck Surg 93:146-147, 1985

25. Hudgins WR, Antes KJ, Herbert MA, Weiner RL, DeSaloms JM, Stamos D, et al: Control of growth of vestibular schwannomas with low-dose Gamma Knife surgery. J Neurosurg 105 Suppl:154-160, 2006

26. Kano H, Kondziolka D, Khan A, Flickinger JC, Lunsford LD: Predictors of hearing preservation after stereotactic radiosurgery for acoustic neuroma. Clinical article. J Neurosurg 111:863-873, 2009

27. Karpinos M, Teh BS, Zeck O, Carpenter LS, Phan C, Mai WY, et al: Treatment of acoustic neuroma: stereotactic radiosurgery vs. microsurgery. Int J Radiat Oncol Biol Phys 54: 1410-1421, 2002
28. Litvack ZN, Norén G, Chougule PB, Zheng Z: Preservation of functional hearing after gamma knife surgery for vestibular schwannoma. Neurosurg Focus 14(5):E3, 2003

29. Lunsford LD, Niranjan A, Flickinger JC, Maitz A, Kondziolka D: Radiosurgery of vestibular schwannomas: summary of experience in 829 cases. J Neurosurg 102 Suppl:195-199, 2005

30. Massick DD, Welling DB, Dodson EE, Scholfield M, Nagaraja $\mathrm{HN}$, Schmalbrock $\mathrm{P}$, et al: Tumor growth and audiometric change in vestibular schwannomas managed conservatively. Laryngoscope 110:1843-1849, 2000

31. McClelland S III, Guo H, Okuyemi KS: Morbidity and mortality following acoustic neuroma excision in the United States: analysis of racial disparities during a decade in the radiosurgery era. Neuro Oncol 13:1252-1259, 2011

32. Myrseth E, Møller P, Pedersen PH, Vassbotn FS, WentzelLarsen T, Lund-Johansen M: Vestibular schwannomas: clinical results and quality of life after microsurgery or gamma knife radiosurgery. Neurosurgery 56:927-935, 2005

33. Nedzelski JM, Canter RJ, Kassel EE, Rowed DW, Tator CH: Is no treatment good treatment in the management of acoustic neuromas in the elderly? Laryngoscope 96:825-829, 1986

34. Niranjan A, Kondziolka D, Lunsford LD: Neoplastic transformation after radiosurgery or radiotherapy: risk and realities. Otolaryngol Clin North Am 42:717-729, 2009

35. Nonaka Y, Fukushima T, Watanabe K, Friedman AH, Sampson JH, McElveen JT Jr, et al: Contemporary surgical management of vestibular schwannomas: analysis of complications and lessons learned over the past decade. Neurosurgery 72 (2 Suppl Operative):ons103-ons115, 2013

36. Norén G: Long-term complications following gamma knife radiosurgery of vestibular schwannomas. Stereotact Funct Neurosurg 70 (Suppl 1):65-73, 1998

37. Ogawa K, Kanzaki J, Ogawa S, Tsuchihashi N, Ikeda S: Progression of hearing loss in acoustic neuromas. Acta Otolaryngol Suppl 487:133-137, 1991

38. Pollock BE: Management of vestibular schwannomas that enlarge after stereotactic radiosurgery: treatment recommendations based on a 15 year experience. Neurosurgery 58:241248, 2006

39. Pollock BE, Lunsford LD, Kondziolka D, Sekula R, Subach BR, Foote RL, et al: Vestibular schwannoma management. Part II. Failed radiosurgery and the role of delayed microsurgery. J Neurosurg 89:949-955, 1998

40. Preston-Martin S, Mack W: Neoplasms of the nervous system, in Schottenfeld D, Fraumeni JF Jr (eds): Cancer Epidemiology and Prevention, ed 2. New York: Oxford University Press, 1996, pp 1231-1281

41. Preston-Martin S, Thomas DC, Wright WE, Henderson BE: Noise trauma in the aetiology of acoustic neuromas in men in Los Angeles County, 1978-1985. Br J Cancer 59:783-786, 1989

42. Régis J, Carron R, Delsanti C, Porcheron D, Thomassin JM, Murracciole X, et al: Radiosurgery for vestibular schwannomas. Neurosurg Clin N Am 24:521-530, 2013

43. Régis J, Carron R, Park MC, Soumare O, Delsanti C, Thomassin JM, et al: Wait-and-see strategy compared with proactive Gamma Knife surgery in patients with intracanalicular vestibular schwannomas. Clinical article. J Neurosurg 113 Suppl:105-111, 2010

44. Régis J, Pellet W, Delsanti C, Dufour H, Roche PH, Thomassin JM, et al: Functional outcome after gamma knife surgery or microsurgery for vestibular schwannomas. J Neurosurg 97:1091-1100, 2002

45. Régis J, Roche PH, Delsanti C, Soumare O, Thomassin JM, Pellet W: Stereotactic radiosurgery for vestibular schwannoma, in Pollock BE (ed): Contemporary Stereotactic Radiosurgery: Technique and Evaluation. Armonk, NY: Futura Publishing, 2002, pp 181-212

46. Régis J, Tamura M, Delsanti C, Roche PH, Pellet W, Thomas- 
sin JM: Hearing preservation in patients with unilateral vestibular schwannoma after gamma knife surgery. Prog Neurol Surg 21:142-151, 2008

47. Roche PH, Noudel R, Régis J: Management of radiation/radiosurgical complications and failures. Otolaryngol Clin North Am 45:367-374, ix, 2012

48. Roche PH, Régis J, Devèze A, Delsanti C, Thomassin JM, Pellet W: [Surgical removal of unilateral vestibular schwannomas after failed Gamma Knife radiosurgery.] Neurochirurgie 50:383-393, $2004(\mathrm{Fr})$

49. Rowe J, Grainger A, Walton L, Silcocks P, Radatz M, Kemeny A: Risk of malignancy after gamma knife stereotactic radiosurgery. Neurosurgery 60:60-66, 2007

50. Ryals BM, Rubel EW: Hair cell regeneration after acoustic trauma in adult Coturnix quail. Science 240:1774-1776, 1988

51. Samii M, Matthies C: Management of 1000 vestibular schwannomas (acoustic neuromas): hearing function in 1000 tumor resections. Neurosurgery 40:248-262, 1997

52. Samii M, Matthies C: Management of 1000 vestibular schwannomas (acoustic neuromas): surgical management and results with an emphasis on complications and how to avoid them. Neurosurgery 40:11-23, 1997

53. Sarmiento JM, Patel S, Mukherjee D, Patil CG: Improving outcomes in patients with vestibular schwannomas: microsurgery versus radiosurgery. J Neurosurg Sci 57:23-44, 2013

54. Schmitt WR, Carlson ML, Giannini C, Driscoll CL, Link MJ: Radiation-induced sarcoma in a large vestibular schwannoma following stereotactic radiosurgery: case report. Neurosurgery 68:E840-E846, 2011

55. Shelton C, Hitselberger WE, House WF, Brackmann DE: Hearing preservation after acoustic tumor removal: long-term results. Laryngoscope 100:115-119, 1990

56. Stangerup SE, Caye-Thomasen P, Tos M, Thomsen J: Change in hearing during 'wait and scan' management of patients with vestibular schwannoma. J Laryngol Otol 122:673-681, 2008

57. Stangerup SE, Caye-Thomasen P, Tos M, Thomsen J: The natural history of vestibular schwannoma. Otol Neurotol 27: 547-552, 2006

58. Stangerup SE, Thomsen J, Tos M, Cayé-Thomasen P: Longterm hearing preservation in vestibular schwannoma. Otol Neurotol 31:271-275, 2010

59. Sughrue ME, Yang I, Han SJ, Aranda D, Kane AJ, Amoils M, et al: Non-audiofacial morbidity after Gamma Knife surgery for vestibular schwannoma. Neurosurg Focus 27(6):E4, 2009

60. Tamura M, Carron R, Yomo S, Arkha Y, Muraciolle X, Porcheron D, et al: Hearing preservation after gamma knife radiosurgery for vestibular schwannomas presenting with highlevel hearing. Neurosurgery 64:289-296, 2009
61. Thomsen J, Terkildsen K, Tos M: Acoustic neuromas. Progression of hearing impairment and function of the eighth cranial nerve. Am J Otol 5:20-33, 1983

62. Tschudi DC, Linder TE, Fisch U: Conservative management of unilateral acoustic neuromas. Am J Otol 21:722-728, 2000

63. Unger F, Walch C, Papaefthymiou G, Eustacchio S, Feichtinger K, Quehenberger F, et al: Long term results of radiosurgery for vestibular schwannomas. Zentralbl Neurochir 63:52-58, 2002

64. Wolbers JG, Dallenga AH, Mendez Romero A, van Linge A: What intervention is best practice for vestibular schwannomas? A systematic review of controlled studies. BMJ Open 3:e001345, 2013

65. Woodson EA, Dempewolf RD, Gubbels SP, Porter AT, Oleson JJ, Hansen MR, et al: Long-term hearing preservation after microsurgical excision of vestibular schwannoma. Otol Neurotol 31:1144-1152, 2010

66. Wowra B, Muacevic A, Jess-Hempen A, Hempel JM, Müller-Schunk S, Tonn JC: Outpatient gamma knife surgery for vestibular schwannoma: definition of the therapeutic profile based on a 10-year experience. J Neurosurg 102 Suppl: 114-118, 2005

67. Yang I, Aranda D, Han SJ, Chennupati S, Sughrue ME, Cheung SW, et al: Hearing preservation after stereotactic radiosurgery for vestibular schwannoma: a systematic review. J Clin Neurosci 16:742-747, 2009

68. Yang I, Sughrue ME, Han SJ, Aranda D, Pitts LH, Cheung SW, et al: A comprehensive analysis of hearing preservation after radiosurgery for vestibular schwannoma. Clinical article. J Neurosurg 112:851-859, 2010

69. Yang I, Sughrue ME, Han SJ, Fang S, Aranda D, Cheung SW, et al: Facial nerve preservation after vestibular schwannoma Gamma Knife radiosurgery. J Neurooncol 93:41-48, 2009

70. Yomo S, Carron R, Thomassin JM, Roche PH, Régis J: Longitudinal analysis of hearing before and after radiosurgery for vestibular schwannoma. Clinical article. J Neurosurg 117: 877-885, 2012

Manuscript submitted June 30, 2014.

Accepted August 6, 2014

Please include this information when citing this paper: DOI: 10.3171/2014.8.GKS141506.

Address correspondence to: Nicola Boari, M.D., Department of Neurosurgery, I.R.C.C.S. San Raffaele Hospital, Via Olgettina 60, Milan 20132, Italy. email: boari.nicola@hsr.it. 